\title{
Modeling of Thermodynamic Properties for Pure Refrigerants and Refrigerant Mixtures by Using the Helmholtz Equation of State and Cubic Spline Curve Fitting Method
}

\author{
Halil Atalay ${ }^{1, *}$, M. Turhan Coban ${ }^{2}$ \\ ${ }^{1}$ Department of Mechanical Engineering, Faculty of Engineering, Bozok University, Turkey \\ ${ }^{2}$ Department of Mechanical Engineering, Faculty of Engineering, Ege University, Turkey
}

Copyright $(\mathcal{C} 2015$ by authors, all rights reserved. Authors agree that this article remains permanently open access under the terms of the Creative Commons Attribution License 4.0 International License

\begin{abstract}
When simulating refrigeration systems or equipment, knowledge of refrigerant thermodynamic properties is required. While some of the refrigerants are made of pure fluids, some of these refrigerants are made by mixing of two or more pure refrigerants with the predetermined percentages. Properties of refrigerants are a major part of international trade, therefore, it is a subject of interest of international standards. In this study a computer model was developed based on Helmholtz equation of state and cubic spline curve fitting models developed by using saturation thermophysical properties of the refrigerants and refrigerant mixtures. Java programming language was used to model equation of state. As an example the equations for R1234yf and R410A were presented in this paper. With the new model, thermodynamic properties of R1234yf and R410A were compared with REFPROP 9.0. It shows that the total mean deviations of the new model are less than $0.5 \%$.
\end{abstract}

Keywords Refrigerants, Thermodynamic Properties, Equation of State, Calculation, R1234yf, R410A

\section{Introduction}

Refrigeration systems become more important for people's daily lives in recent decades, and more refrigeration products are designed every year, which requires the design of refrigeration products to be more efficient. One of the effective ways to improve the design efficiency for refrigeration products is to use the computer simulations. With the computer simulation methods, models of different components of the refrigeration products to be simulated must be built, and the models for thermodynamic properties of refrigerants are very important and indispensable one.

Accurate knowledge of thermodynamic properties is of great importance in the design of refrigeration equipment. Since it is not possible to measure every refrigerant property of interest at every combination of temperature and pressure, refrigerant properties are usually determined with some sort of mathematical model. According to McLinden et al. [20], a properly formulated equation of state was capable of reproducing experimental property data within the experimental uncertainty of the data and also yields through integration and differentiation, all of the thermodynamic properties of interest. Even though there are number of equations of state models that have the abilities mentioned, these formulations present the disadvantage of their low computational speed and that most of the thermodynamic properties equations are implicit and require more iterations. The traditional methods based on equation of state cannot meet such requirement because of unavoidable iterations in calculation. But, calculations of thermal properties of refrigerants are desired to be very fast, accurate and stable in cases of simulation of refrigeration system, etc. Therefore, the engineering calculation and simulation of refrigeration systems require the availability of simple and efficient mathematical models for the determination of thermodynamic properties of refrigerants.

When simulating refrigeration systems or equipment, the thermodynamic properties have to be determined a large number of times and sometimes their calculation is required within iteration loops. Clear examples are dynamic simulation of refrigeration systems or finite element analyses of refrigeration equipment. Therefore, in order to improve the computation stability, different authors presented explicit or hybrid formulations for several pure and mixture refrigerants (Chan et al.[2], Chartes et al.[3],Cleland et al. [4,5], Devotta et al.[6], Ding et al.[7], Fernandes et al.[9],Huber et al.[11]).

In the works of Ding et al. [7,8], implicit equations were proposed to calculate different kinds of thermal properties. 
The coefficients of the implicit equations were determined by curve-fitting methods, using REFPROP 6.0 to generate the source data. The highest variable order of the polynomial of the implicit equations that they were used, so explicit formulae for the different variables could be obtained.

Recently, intelligent some computer models for calculating thermodynamic properties of refrigerants have been improved. Akasaka et al. [1] presented a timely and reliable equation of state for 2, 3, 3, 3-tetrafluoropropane (HFO-1234yf). They used Patel Teja equation of state and the extended corresponding state(ECS) model have been individually applied to property modeling for this refrigerant. Tanaka et.al.[29] measured thermodynamic properties of HFO-1234yf. Especially, they measured critical temperature, critical density and critical pressure with the visual observation of the meniscus disappearance and they determined to be $367,85 \mathrm{~K}, 478 \mathrm{~kg}^{*} \mathrm{~m}^{-3}$ and 3382 $\mathrm{kPa}$ respectively. They used Peng-Robinson Equation for based on the critical parameters. Richter et.al. [22] measured $\mathrm{p}-\rho$-T behavior of 2,3,3,3-tetrafluoroprop-1-ene (R1234yf) from $\mathrm{T}=(232$ to 400$) \mathrm{K}$ with pressures up to 10 MPa using a two-sinker densimeter, extend from low-density vapor to compressed-liquid states and include the extended critical region. They used Helmholtz energy equations for calculation of thermodynamic properties of R1234yf. Monte et.al. [21] developed of the thermodynamic properties of two mixtures of hydrofluorocarbon (HFC) refrigerants,i.e. R407C and R410A(in the superheated vapor state)was carried out. He used Martin-Hou equation of state for the calculation. Sozen et.al.[25] determinated thermodynamic properties of an alternative refrigerant (R407C) using artifical neural network. Froba et.al.[10] measured thermophysical properties of the refrigerant mixtures R410A and $\mathrm{R} 407 \mathrm{C}$ using dynamic light scattering.

Helmholtz free energy mixing law has been recognized as the best mixing law until now. Lemmon and Tillner-Roth [15] and Lemmon and Jacobsen [16] applied it to the thermo physical properties estimation of mixture R32 /R125/R134a with an absolute average deviation within $0,3 \%$.

Küçüksille et al.[13] used Data Mining for the determination of thermodynamic properties as enthalpy, entropy, specific volume values for any temperature and pressure of alternative refrigerants. The method proposed offered more flexibility, and therefore thermodynamic simulation of vapor compression refrigeration systems was fairly simplified. Saleh et al. [23] used BACKONE equations to screening of pure fluids as alternative refrigerants. The coefficients of the implicit equations were determined by curve-fitting method, using REFPROP 7.1 to generate to source data.

Sieres et al. [24] used a hybrid formulation for the calculation of thermodynamic properties of pure refrigerants and refrigerant mixtures. Implicit polynomial equations of order three were used for curve fitting of the main thermodynamic properties. Then, explicit formulae for the related properties were obtained. The formulation was similar to that of Ding and co-workers, though some differences existed in the transformation of the thermodynamic properties before the regression analysis was performed near the critical point in the mathematical treatment. Mahajan et al. [18] presented a new predictive method for estimation of accurate thermodynamic properties of the liquid-vapor coexistence states. Calculated values of vapor pressure and saturated liquid density for argon, nitrogen, ethylene, oxygen, fluorine, methane, dichlorodifluoromethane (R12) and propane were used to demonstrate the method. Zhao et al. [32] presented the implicit curve-fitting method for fast and stable calculations of thermodynamic properties of subcritical refrigerants, and used it at the saturated liquid or vapor state as the reference state. With the new method, thermodynamic properties of supercritical $\mathrm{CO}_{2}$ and $\mathrm{R} 410 \mathrm{~A}$ were predicted and compared with REFPROP 8.0.

Mathematical expressions for the derivatives of the residual Helmholtz energy were presented elsewhere(Akasaka et al.[1], Richter et al.[22]). From the derivatives, all thermodynamic properties of the fluid of interest could have derived. The literature summarized the relation between common thermodynamic properties and the derivatives of the Helmholtz energy, e.g., Lemmon and Jacobsen [17], Span [26] and Tillner-Roth et al. [30]. According to Tillner-Roth et al. [31] Helmholtz energy model could have represented a system with the highest accuracy using the fewest coefficients. However, it was specific to the R32/ 134a system and could not have extended to ternary systems using the current functional form.

In this study, in order to calculate accurately thermodynamic properties as an enthalpy, entropy, internal energy, specific volume, density, quality values for any temperature and pressure of pure refrigerants, a new computer program was developed. This model was obtained for the base of ISO 17584 Helmholtz equation of state (HEOS) and cubic spline curve fitting method (CSCFM). In this study, one of these methods $(H E O S)$ was used to calculate the thermodynamic properties in subcooled liquid and superheated vapor phases, and the other (CSCFM) to calculate the thermodynamic properties in saturated liquid vapor phases. The objective was to have these methods that meet the following requirements: accurate and stable computation of thermal properties; Helmholtz equations and cubic spline curve fitting equations, so iterative numerical methods were not required; reversibility of these equations, so the calculation of the related parameters from different Helmholtz and curve fitting formulas were reversible; same format of the all equations used, so the method could have been easily programmed and adjusted to multiple refrigerants.

Although many works related with the thermodynamic properties of some refrigerants and refrigerant mixtures have taken place in the literature until now, there was a limited data for these refrigerants. Therefore, as an example, the 
equations for R1234yf and R410A refrigerants were presented in this paper and also thermodynamic properties of these refrigerants based on three phases were calculated in the developed program. The results for these refrigerants were obtained from the REFPROP 9.0 as a supplementary data to compare with the developed program.

\section{Calculation Methods}

In this paper, we utilized two methods for calculating of refrigerants thermodynamic properties. These are International ISO17584 Helmholtz Equation of State (HEOS) and Cubic spline curve fitting method (CSCFM). The first method (HEoS) was used for calculating thermodynamic properties in subcooled and superheated regions and the other (CSCFM) was used for calculating thermodynamic properties at saturated liquid, saturated vapor lines and in saturated liquid-vapor mixed region.

\subsection{International ISO17584 Helmholtz Equation of State}

International Standard specifies thermo physical properties of several commonly used refrigerants. This international standard is applicable to the refrigerants R12, R22，R32，R123，R125，R134a，R143a，R152a，R717 (ammonia) and R744 (carbon dioxide) and to the refrigerant blends R404A, R407C, R410A and R507A [12]. Richter et.al. [22] measured thermodynamic properties of R1234yf using Helmholtz energy as the fundamental property with independent variables of density and temperature. The fit started with the "short form" equation of state of Span and Wagner[27].The equations is similar to international standard equations. The following properties are included: density, pressure, internal energy, enthalpy, entropy, in both single- phase states (sub cooled and superheated) and along the liquid-vapor saturation boundary. An equation of state for a pure fluid may express the reduced molar Helmholtz energy, $A$, as a function of temperature and density. The equation was composed of separate terms arising from ideal-gas behavior (subscript"id") and a "residual" or "real-fluid" (subscript " $r$ ") contribution as given in Equation (2.1):

$$
\phi=\frac{A}{R T}=\phi_{i d}(\rho, T)+\phi_{r}(\rho, T)
$$

Where $R$ is a gas constant. The "residual" or "real-fluid" contribution was given by Equation (2.2):

$\phi_{r}=\sum_{k} N_{k} \tau^{t_{k}} \delta^{d_{k}} \exp \left[-\alpha_{k}\left(\delta-\varepsilon_{k}\right)^{l_{k}}\right] \exp \left[-\beta_{k}\left(\tau-\gamma_{k}\right)^{m_{k}}\right]$

This equation for R1234yf was given in (2.2.a);

$$
\begin{aligned}
& \phi_{r}=\sum_{k=1}^{5} N_{k} \tau^{t k} \delta^{d k}+\sum_{k=6}^{10} N_{k} \tau^{t k} \delta^{d k} \exp \left(-\delta^{l k}\right)+ \\
& \sum_{k=11}^{15} N_{k} \tau^{t k} \delta^{d k} \exp \left[-\alpha_{k}\left(\delta-\varepsilon_{k}\right)^{2}-\beta_{k}\left(\tau-\gamma_{k}\right)^{2}\right]
\end{aligned}
$$

The ideal-gas contribution can be represented in one of several ways. One representation was in terms of the heat capacity of the ideal-gas state, as given in Equation (2.3):

$$
\begin{aligned}
& \phi_{i d}=\frac{h_{r e f}}{R T}-\frac{s_{r e f}}{R}-1+\ln \left(\frac{R T \rho}{P_{r e f}}\right)+ \\
& +\frac{1}{R T} \int_{T_{r e f}} C_{p, i d} d T-\frac{1}{R} \int_{T_{r e f}}^{T} \frac{C_{p, i d}}{T} d T
\end{aligned}
$$

Where $h_{\text {ref }}$ is the arbitrary reference enthalpy for the ideal gas at the reference state specified by $T_{r e f}$ and $s_{r e f}$, is the arbitrary reference entropy for the ideal gas at the reference state specified by $T_{r e f}$.

The heat capacity of the ideal gas state, $C_{p, i d}$ was represented as a function of temperature by the general form consisting of separate summations of polynomial (empirical) and exponential (theoretical) terms, as given in Equation (2.4):

$$
\frac{C_{p, i d}}{R}=c_{0}+\sum_{k} c_{k} T^{t_{k}}+\sum_{k} a_{k} \frac{u_{k}^{2} \exp \left(u_{k}\right)}{\left[\exp \left(u_{k}\right)-1\right]^{2}}
$$

Where,

$$
u_{k}=\frac{b k}{T}
$$

A second representation of the ideal-gas contribution was given directly in terms of the Helmholtz free energy, as shown in Equation (2.6):

$$
\begin{aligned}
& \phi_{i d}=f_{1}+\frac{f_{2}}{T}+\ln (\rho)+\left(1-C_{0}\right) \ln (T)- \\
& -\sum_{k} C_{k}\left(\frac{1}{t_{k}+1}\right)\left(\frac{1}{t_{k}}\right) T^{t_{k}}+\sum_{k} a_{k} \ln \left(1-\exp \left(\frac{b_{k}}{T}\right)\right)
\end{aligned}
$$

This equation for R1234yf was given in 2.6.a;

$\phi_{i d}=f_{1}+f_{2} \tau+\ln \delta+4.944 \ln \tau+\sum_{k=1}^{4} v_{k} \ln \left[1-\exp \left(-\frac{u_{k} \tau}{T c}\right)\right]$

Where;

$f_{l}, f_{2}, C_{0}, C_{k}, a_{k}, b_{k}, t_{k}, u_{k}, v_{k}$ are either empirical or theoretical parameters.

Thermodynamic properties of mixtures are calculated by applying mixing rules to the Helmholtz energy of the mixture components together with a separate mixture function. The reduced Helmholtz energy of the mixture is a sum of ideal-gas and residual contributions as given by Equation (2.7): 


$$
\phi_{m i x}=\frac{A}{R T}=\phi_{m i x, i d}(\rho, T)+\phi_{m i x, r}(\rho, T)
$$

The ideal gas part was given by equation (2.8);

$$
\phi_{\text {mix }, i d}=\sum_{i=1}^{n}\left(x_{i} \phi_{i, i d}+x_{i} \ln x_{i}\right)+f_{3}+f_{4} / T
$$

$f_{3}, f_{4}$ are either empirical or theoretical parameters.

The residual part was given by equation (2.9);

$$
\phi_{\text {mix }, r}=\sum_{i=1}^{n} x_{i} \phi_{i, r}+\sum_{i=1}^{n-1} \sum_{j=i+1}^{n} x_{i} x_{j} \phi_{i j, \text { excess }}
$$

The first summation in this equation represents the ideal solution; it consists of the real fluid terms for each of the pure fluids multiplied by their respective compositions. The double summation accounts for the "excess" Helmholtz energy or "departure" from ideal solution. The $\varphi_{i, r}$ and $\varphi_{\mathrm{ij}, \text { excess }}$ functions in Equation (2.9) are not evaluated at the temperature, $T_{m i x}$, and density, $\rho_{m i x}$, of the mixture, but, rather, at a reduced temperature, $\tau$ and density, $\delta$. The mixing rules for the reducing parameters are given by Equations (2.10) and (2.11):

$$
\tau=\frac{T^{*}}{T_{m i x}}
$$

where;

$$
\begin{gathered}
T^{*}=\sum_{i=1}^{n} x_{i} T_{i}^{*}+\sum_{i=1}^{n-1} \sum_{j=i+1}^{n} x_{i} x_{j} \zeta_{i j} \\
\delta=\frac{\rho_{\text {mix }}}{\rho^{*}}
\end{gathered}
$$

where;

$$
\frac{1}{\rho^{*}}=\sum_{i=1}^{n} \frac{x_{i}}{\rho_{i}^{*}}+\sum_{i=1}^{n-1} \sum_{j=i+1}^{n} x_{i} x_{j} \xi_{i j}
$$

The $\varphi_{\mathrm{ij}, \text { excess }}$ function is of the general form of equation (2.12);

$$
\varphi_{i j, \text { excess }}=F_{i j} \sum_{k} N_{k} \delta^{d k} \tau^{t k} \exp \left(-\delta^{l k}\right)
$$

Starting with an equation of state explicit in reduced Helmholtz energy for pure fluids, e.g. Equations (2.1) to (2.6), the thermodynamic properties were given by the following; [12]

$$
\begin{array}{r}
P=R T \rho\left(1+\delta \frac{\partial \phi_{r}}{\partial \delta}\right) \\
u=R T\left(\tau \frac{\partial \phi_{i d}}{\partial \tau}+\tau \frac{\partial \phi_{r}}{\partial \tau}\right)
\end{array}
$$

$$
\begin{gathered}
h=R T\left(1+\tau \frac{\partial \phi_{i d}}{\partial \tau}+\tau \frac{\partial \phi_{r}}{\partial \tau}+\delta \frac{\partial \phi_{r}}{\partial \delta}\right) \\
s=R\left(-\left(\phi_{i d}+\phi_{r}\right)+\tau \frac{\partial \phi_{i d}}{\partial \tau}+\tau \frac{\partial \phi_{r}}{\partial \tau}\right) \\
g=R T\left(1+\phi_{i d}+\phi_{r}+\delta \frac{\partial \phi_{r}}{\partial \delta}\right) \\
C_{v}=R\left(-\tau^{2} \frac{\partial^{2} \phi_{i d}}{\partial \tau^{2}}-\tau^{2} \frac{\partial^{2} \phi_{r}}{\partial \tau^{2}}\right) \\
C_{p}=C_{v}+R \frac{\left(1+\delta \frac{\partial \phi_{r}}{\partial \delta}-\delta \tau^{2} \frac{\partial^{2} \phi_{r}}{\partial \tau \partial \delta}\right)}{1+2 \delta \frac{\partial \phi_{r}}{\partial \delta}+\delta^{2} \frac{\partial^{2} \phi_{r}}{\partial \delta^{2}}}
\end{gathered}
$$

Starting with the mixture equation of state explicit in reduced Helmholtz energy, Equations (2.7) to (2.12), the thermodynamic properties of mixtures are given by the same expressions as for pure fluids [Equations (2.13) to (2.19)], except that the derivatives of the residual part are composed of contributions from the pure components and the excess function.

As it is seen from that the equation Helmholtz free energy type of equation of states were required only derivatives to obtain properties, therefore they were easier to simulate in computer programs compare to pressure type of equation of states.

Saturated regions equations can be obtained equation of state;

$$
\begin{gathered}
P\left(\tau, \delta_{\text {liq }}\right)=P\left(\tau, \delta_{\text {vap. }}\right) \\
g\left(\tau, \delta_{\text {liq. }}\right)=g\left(\tau, \delta_{\text {vap. }}\right)
\end{gathered}
$$

As mentioned by Ding et al. [8], for most of refrigeration applications, the subcooling of refrigerants are limited, so the following formulae can be used for linking the temperature, enthalpy and entropy of a sub cooled liquid when the pressure $\mathrm{P}$ (or the saturation temperature) was given as an input parameter:

$$
\begin{array}{r}
h=h_{l s}-C_{p l s}\left(T_{l s}-T\right) \\
s=s_{l s}-C_{p l s}\left(T_{l s} / T\right)
\end{array}
$$

The variables $h_{l s}, s_{l s}$ and $C p_{l s}$ represent saturated liquid thermal properties for saturated pressure $\left(P_{\text {sat }}\right)$, which were calculated from Helmholtz equations in section 2.1.

\subsection{Cubic Spline Curve Fitting Method}

Cubic spline curve fitting method was used in transforming the saturation data into the curves for the calculation of the thermodynamic properties in the saturation region. If the cubic spline function was given in this form; 


$$
s_{k}(x)=a_{k}\left(x-x_{k}\right)+b_{k}\left(x_{k+1}-x\right)+\left[c_{k+1}\left(x-x_{k}\right)^{3}++c_{k}\left(x_{k+1}-x\right)^{3}\right] /\left(6 h_{k}\right) \quad 1 \leq \mathrm{k} \leq \mathrm{n}
$$

the derivative equations were given below:

$$
\begin{gathered}
s_{k}^{\prime}(x)=a_{k}-b_{k}+\left[c_{k+1}\left(x-x_{k}\right)^{2}-c_{k}\left(x_{k+1}-x\right)^{2}\right] /\left(2 h_{k}\right) 1 \leq \mathrm{k} \leq \mathrm{n} \\
s_{k}^{\prime \prime}(x)=\left[c_{k+1}\left(x-x_{k}\right)+c_{k}\left(x_{k+1}-x\right)\right] /\left(h_{k}\right) \quad 1 \leq \mathrm{k} \leq \mathrm{n}
\end{gathered}
$$

Here $c_{\mathrm{k}}$ can be written as a function of $a_{k}$ and $b_{k}$.

$$
\begin{gathered}
b_{k}=\left[6 y_{k}-h_{k} c_{k}\right] /\left(6 h_{k}\right), 1 \leq k \leq n \\
a_{k}=\left[6 y_{k+1}-h_{k}{ }^{2} c_{k+1}\right] /\left(6 h_{k}\right), 1 \leq k \leq n
\end{gathered}
$$

In this case, the system of equation to be solved was converted into terms involving only $c_{k}$.

$$
\mathrm{h}_{\mathrm{k}-1} \mathrm{c}_{\mathrm{k}-1}+2\left(\mathrm{~h}_{\mathrm{k}-1}-\mathrm{h}_{\mathrm{k}}\right) \mathrm{c}_{\mathrm{k}}+\mathrm{h}_{\mathrm{k}} \mathrm{c}_{\mathrm{k}+1}=6\left[\frac{y_{k+1}-y_{k}}{h_{k}}-\frac{y_{k}-y_{k-1}}{h_{k-1}}\right], 1 \leq \mathrm{k} \leq \mathrm{n}
$$

In this system, there are totally $n-2$ equations;

$$
w_{k}=\frac{y_{k+1}-y_{k}}{h_{k}}, 1 \leq \mathrm{k} \leq \mathrm{n}
$$

If the above definition is given, the following matrix form will be taken to solve the equation system:

$$
\left[\begin{array}{ccccccc}
1 & 0 & 0 & \ldots & 0 & 0 & 0 \\
h_{1} & 2\left(h_{1}+h_{2}\right) & h_{2} & \ldots & 0 & 0 & 0 \\
0 & h_{2} & 2\left(h_{2}+h_{3}\right) & \ldots & 0 & 0 & 0 \\
\ldots & \ldots & \ldots & \ldots & \ldots & \ldots & \ldots \\
0 & 0 & 0 & \ldots & 2\left(h_{n-3}+h_{n-2}\right) & h_{n-2} & 0 \\
0 & 0 & 0 & \ldots & h_{n-2} & 2\left(h_{n-2}+h_{n-1}\right) & h_{n-1} \\
0 & 0 & 0 & \ldots & 0 & 0 & 1
\end{array}\right]\left[\begin{array}{c}
c_{0} \\
c_{1} \\
c_{2} \\
\ldots \\
c_{n-2} \\
c_{n-1} \\
c_{n}
\end{array}\right]=\left[\begin{array}{c}
A \\
6\left(w_{2}-w_{1}\right) \\
6\left(w_{3}-w_{2}\right) \\
\ldots \\
6\left(w_{n-2}-w_{n-3}\right) \\
6\left(w_{n-1}-w_{n-2}\right) \\
B
\end{array}\right]
$$

Here, A and B are the boundary conditions for the second derivative which should be defined by the user. In our model, $\mathrm{A}$ and $\mathrm{B}$ is taken as zero (natural cubic spline). This system of equation constitutes a practical system as it has a small margin of error when it is solved for the chart data.

\section{Description of Developed Computer Program}

In order to evaluate thermodynamic properties of refrigerants by using equations given in section 2 , a new computer program (refrigerant) was developed on a java computer program language. Thermodynamic properties in subcooled and superheated regions were designed in java class "RefISO17584" by using Helmholtz Equation of state [12]. Also, thermodynamic properties of refrigerant on the saturation liquid, saturation vapor lines and in the saturation liquid-vapor phase were designed in java class "ref_CS3" by using cubic spline curve fitting method directly taken from the ASHRAE [28]. Thermodynamic properties were defined as a temperature, pressure, enthalpy, entropy, internal energy, density, specific volume, quality of pure refrigerants, etc. Computer simulation code should be able to work with any two pair of known thermodynamic properties as input parameters. Simulation program includes sets of root solving methods to obtain solutions of EOS for different thermodynamic input pairs. The thermodynamic known property sets in the model is as follows: $\boldsymbol{t} x$, TemperatureQuality; $\boldsymbol{t} \boldsymbol{p}$ or $\boldsymbol{p t}$, Temperature- Pressure; $\boldsymbol{t} \boldsymbol{v}$ or $\boldsymbol{v t}$, Temperature- Specific Volume; $\boldsymbol{t} \boldsymbol{h}$, Temperature- Enthalpy; $\boldsymbol{t} \boldsymbol{u}$, Temperature- Internal Energy; $\boldsymbol{t} \boldsymbol{s}$, Temperature- Entropy; $\boldsymbol{p} \boldsymbol{v}$ or $\boldsymbol{v p}$, Pressure- Specific Volume; $\boldsymbol{p h}$, Pressure- Enthalpy; $\boldsymbol{p} \boldsymbol{u}$, Pressure- Internal Energy; $\boldsymbol{p s}$, Pressure- Entropy; $\boldsymbol{p} \boldsymbol{x}$, Pressure- Quality. In order to use the thermodynamic properties in a java program, a code similar to following should be called:

\section{refrigerant st=new refrigerant ("R1234yf"); \\ double temperature $=10,0$; \\ double pressure $=\mathbf{5 0 , 0}$;}

double a[]=st. property(“t $t p$ ”, temperature, pressure).

If the above code is called in a program, all the thermodynamic properties will be loaded into the double array which contains the thermodynamic variables as: a[0], $P$ - pressure $\mathrm{kPa} ; \mathrm{a}[1], t$ - temperature ${ }^{0} \mathrm{C} ; \mathrm{a}[2], v$ - specific volume $\mathrm{m}^{3} \mathrm{~kg}^{-1} ; \mathrm{a}[3], h$ - enthalpy $\mathrm{kj} \mathrm{kg}^{-1} ; \mathrm{a}[4], u$ - internal energy $\mathrm{kj} \mathrm{kg}^{-1} ; \mathrm{a}[5], s$ - entropy $\mathrm{kj} \mathrm{kg}^{-1} \mathrm{~K}^{-1} ; \mathrm{a}[6], x$ - quality (kg vapor)(kg total phase $)^{-1} ; \mathrm{a}[7], \rho$ - density $\mathrm{kgm}^{-3}$. A user interface class "refTable" was also developed to use as standalone program. A demonstration of refrigerant.java interface programs were given in Figure 1 and, also output of the program code was shown in figure 1. 


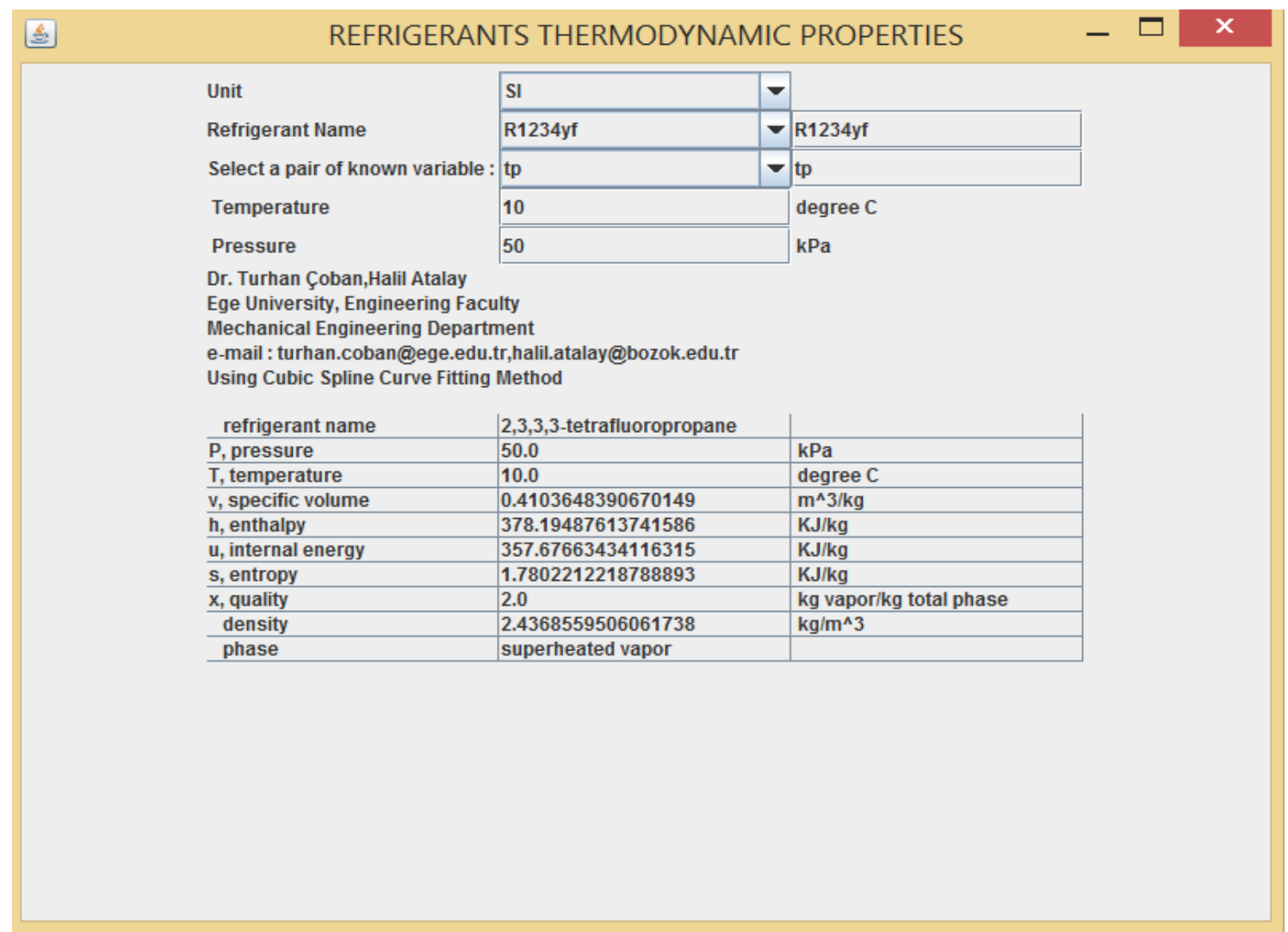

a-) $\mathrm{R} 1234 \mathrm{yf}$ refrigerant in superheated vapor region at $\mathrm{T}=10 \mathrm{C}$ and $\mathrm{P}=50 \mathrm{kPa}$

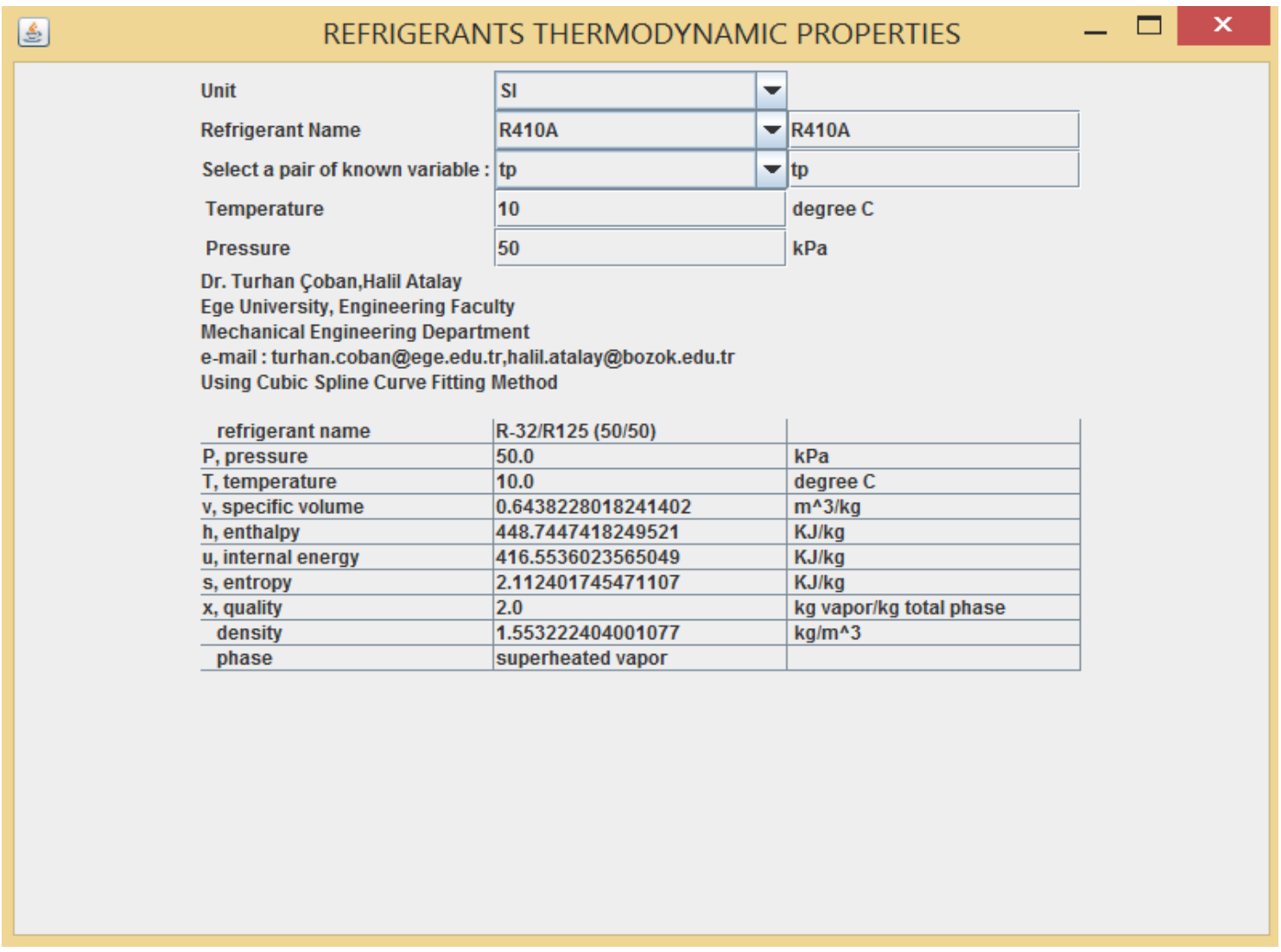

b-) $\mathrm{R} 410 \mathrm{~A}$ refrigerant mixture in superheated vapor region at $\mathrm{T}=10 \mathrm{C}$ and $\mathrm{P}=50 \mathrm{kPa}$

Figure 1. A demonstration of Refrigerant.java interface programs (RefISO17584Table. java) for calculating R1234yf and R410A refrigerants thermodynamic properties as pressure $(\mathrm{P})$, temperature( $\mathrm{T})$, specific volume(v), enthalpy(h), internal energy(u), entropy(s), quality(x), density and phase. 
The new developed program can be used for all three regions (subcooled, mix-phase, superheated and saturated lines of refrigerant fluid). The user can select the application range for any refrigerant to be obtained thermodynamic properties according the specific need of the user, at first. Then, the user can obtain the thermodynamic properties of the selected fluid with the proposed program in the specific range.

\section{Modeling Results and Discussion}

In this study, two mathematical approaches were used for calculating pure refrigerants thermodynamic properties. In the saturated region; saturated liquid, saturated vapor and mixed phase, Cubic spline curve fitting method (CSCFM) was applied to obtain more accurate results. The data source for applying Cubic spline curve fitting method in the developed program comes from actual value tables [31]. The other method, Helmholtz equation of state $(H E O S)$ was applied to obtain more appropriate thermodynamic properties in the subcooled liquid and superheated regions.

R1234yf and R410A were selected as a representative refrigerant to illustrate how to use the new developed program for the determination of thermal properties in this study. Considering the usual application conditions of R1234yf, the expected application range of temperature was changed between $233 \mathrm{~K}$ and $448 \mathrm{~K}$ at superheated region, between $238 \mathrm{~K}$ and $410 \mathrm{~K}$ at subcooled region, between 230 $\mathrm{K}$ and $360 \mathrm{~K}$ at saturated region of R1234yf refrigerant. Similarly, considering the usual application conditions of R410A, the expected application range of temperature was changed between $185 \mathrm{~K}$ and $460 \mathrm{~K}$ at superheated region, between $185 \mathrm{~K}$ and $333 \mathrm{~K}$ at subcooled region, between 185 $\mathrm{K}$ and $345 \mathrm{~K}$ at saturated region of $\mathrm{R} 410 \mathrm{~A}$ refrigerant mixture. A regular increase in the saturation temperature of refrigeration was used for the fitting and accuracy evaluation process. Absolute and mean deviations were evaluated for every thermodynamic properties of R1234yf and R410A in all three regions.

The source data for regressing was obtained from REFPROP 9.0. With the new developed program, thermodynamic properties of R1234yf and R410A for all regions were predicted and compared with REFPROP 9.0 [14]. Because REFPROP 9.0 is widely used for predicting thermodynamic properties of refrigerants, which is based on the most accurate pure fluid and mixture models currently available, and the uncertainty in density, entropy and enthalpy for R1234yf and R410A is within $0,5 \%$. Therefore, REFPROP 9.0 was used to generate data source for regression, and the accuracy was also compared with REFPROP 9.0.

In order to assess the accuracy of the proposed program, a finer temperature spacing of $10 \mathrm{~K}$ in superheated region for $\mathrm{R} 410 \mathrm{~A}, 5 \mathrm{~K}$ in superheated, subcooled and saturated region for R1234yf and $5 \mathrm{~K}$ in subcooled and saturated region for R410A was used. However, in the vicinity of the critical point, the saturated thermal properties vary dramatically, and are not known accurately or even cannot be determined by REFPROP 9.0. For these reasons, this region of the saturation curve was excluded from the analysis.

\subsection{Data Ranges and Parameters of a Refrigerant Fluid}

The range of the thermodynamic properties include subcooled, saturated, two-phase and superheated refrigerant with the pressure up to the critical pressure, shown as regions in Fig. 2. This figure is a sketch of the $p$-h diagram of every refrigerant. The trait shown in Fig. 2 prevail R1234yf and R410A refrigerants considered in this paper. The regions where the superheated, saturated, mix phases and subcooled refrigerant thermal properties were determined, were shown in Fig. 2. These regions were bounded at the bottom and top by the minimum saturation pressure $\left(P_{\min }\right)$ and the critical pressure, respectively. The minimum pressure considered was that of a saturated liquid at $T_{\min }=230 \mathrm{~K}$ for R1234yf and $T_{m i n}=184,92 \mathrm{~K}$ for R410A refrigerant.

Super heated region was bounded at the left and right, by the saturated vapor curve and a constant superheat degree curve $\left(\Delta T_{s h}\right)$, respectively. The range of the saturated thermodynamic properties include saturated liquid and vapor thermal properties, with pressures up to the critical pressure, as shown in Fig. 2. As it can be seen, saturated line bounded as the right-hand part and the left-hand part of the dome of the saturation curve overhangs from the critical point to $P_{\min }$. Also, two-phase region (vapor-liquid equilibrium) is a zone bounded between saturated liquid line and saturated vapor line. The subcooled fluid is defined as a region on the left-hand side of the saturated liquid line.

In this study, the region bounded from the $P_{A}=3000 \mathrm{kPa}$ to $P_{B}=5 \mathrm{kPa}$ for R1234yf in all phases, $P_{A}=1500 \mathrm{kPa}$ to $P_{B}=10$ $\mathrm{kPa}$ for R410A in superheated region and $P_{A}=4900 \mathrm{kPa}$ to $P_{B}=10 \mathrm{kPa}$ for R $410 \mathrm{~A}$ in subcooled and saturated regions on the sketch of the $\mathrm{p}$-h diagram was used for calculating thermal properties. Coefficient values of R1234yf refrigerant were given in table 1 and table 2 for superheated and saturated thermal properties, as an ideal and real gas. These coefficients are valid within the following ranges: $T_{\min }=200 \mathrm{~K}, T_{\max }=400 \mathrm{~K}, P_{\max }=10 \mathrm{MPa}, \rho_{\max }=4.17 \mathrm{~mol} \mathrm{l}^{-1}$ $\left(475,55 \mathrm{~kg} \mathrm{~m}^{-3}\right)$. In order to ensure the accuracy of the new program, all the coefficients were in the format of double precision in programming and so have long digits. An equation of state for pure fluid may express the reduced molar Helmholtz energy, as a function of temperature and density. In equation of states, critical parameters and physical properties of R1234yf were used for reducing molar Helmholtz energy. Reducing Parameters, molar mass and gas constant were given as: $T^{*}=367,85 \mathrm{~K}, \rho^{*}=4,17 \mathrm{~mol} \mathrm{l}^{-1}$, $M=114,04159 \mathrm{~g}(\mathrm{~mol})^{-1}, R=8,314471 \mathrm{~J}(\mathrm{~mol} . \mathrm{K})^{-1}$. 


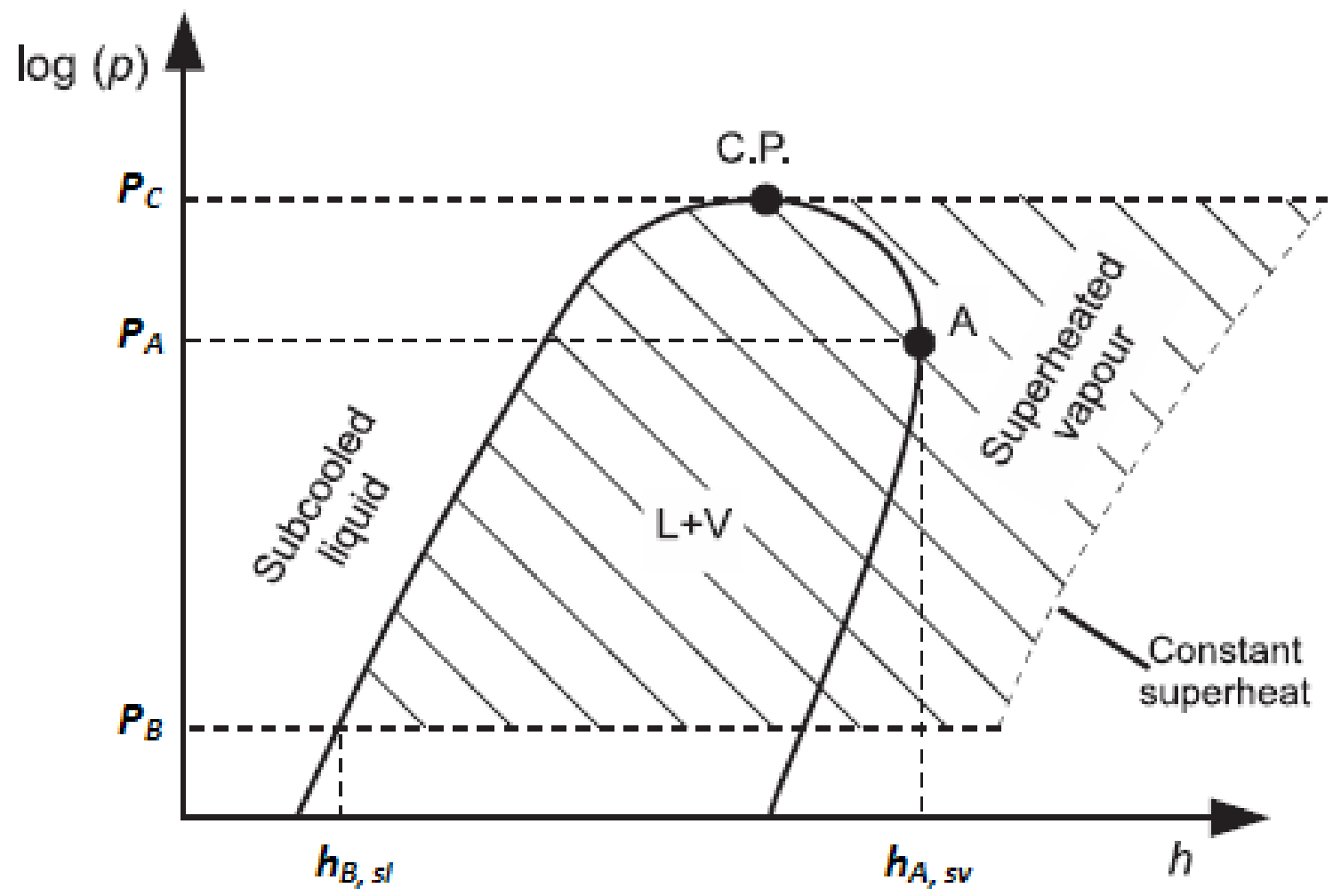

Figure 2. Range of application of subcooled, saturated and superheated refrigerant thermal properties on the pressure - enthalpy diagram: $(\mathrm{L}+\mathrm{V})$ liquid -vapor phase, (C.P.) critical point, $\left(h_{B, s l}\right)$ saturated liquid enthalpy in pressure $P_{B},\left(h_{A, s v}\right)$ saturated vapor enthalpy in pressure $P_{A},\left(P_{C}\right)$ critical point pressure, $\left(P_{A}\right.$ and $\left.P_{B}\right)$ maximum and minimum operating range pressures in the proposed program

Table 1. Values for $v_{i}$ and $u_{i}$ in equation 2.6.a

\begin{tabular}{|c|c|c|}
\hline $\mathrm{i}$ & $v_{i}$ & $u_{i}$ \\
\hline 1 & 7,549 & 718,0 \\
\hline 2 & 1,537 & 877,0 \\
\hline 3 & 2,030 & 4465,0 \\
\hline 4 & 7,455 & 1755,0 \\
\hline
\end{tabular}

Table 2. Coefficients and exponents of the real gas part for R1234yf refrigerant

\begin{tabular}{|c|c|c|c|c|c|c|c|c|}
\hline$k^{a}$ & $N_{k}{ }^{b}$ & $t_{k}^{d}$ & $d_{k}{ }^{d}$ & $I_{k}^{d}$ & $\boldsymbol{\alpha}_{k}^{c}$ & $\boldsymbol{B}_{k}{ }^{c}$ & $\gamma_{k}^{c}$ & $\varepsilon_{k}^{c}$ \\
\hline 1 & 0,04592563 & 1,0 & 4 & 0 & 0 & 0 & 0 & 0 \\
\hline 2 & 1,546958 & 0,32 & 1 & 0 & 0 & 0 & 0 & 0 \\
\hline 3 & $-2,355237$ & 0,929 & 1 & 0 & 0 & 0 & 0 & 0 \\
\hline 4 & $-0,4827835$ & 0,94 & 2 & 0 & 0 & 0 & 0 & 0 \\
\hline 5 & 0,1758022 & 0,38 & 3 & 0 & 0 & 0 & 0 & 0 \\
\hline 6 & $-1,210006$ & 2,28 & 1 & 2 & 0 & 0 & 0 & 0 \\
\hline 7 & $-0,6177084$ & 1,76 & 3 & 2 & 0 & 0 & 0 & 0 \\
\hline 8 & 0,685262 & 0,97 & 2 & 1 & 0 & 0 & 0 & 0 \\
\hline 9 & $-0,6968555$ & 2,44 & 2 & 2 & 0 & 0 & 0 & 0 \\
\hline 10 & $-0,02695779$ & 1,05 & 7 & 1 & 0 & 0 & 0 & 0 \\
\hline 11 & 1,389966 & 1,4 & 1 & 0 & 1,02 & 1,42 & 1,13 & 0,712 \\
\hline 12 & $-0,4777136$ & 3,0 & 1 & 0 & 1,336 & 2,31 & 0,67 & 0,910 \\
\hline 13 & $-0,1975184$ & 3,5 & 3 & 0 & 1,055 & 0,89 & 0,46 & 0,677 \\
\hline 14 & $-1,147646$ & 1,0 & 3 & 0 & 5,84 & 80,0 & 1,28 & 0,718 \\
\hline 15 & 0,0003428541 & 3,5 & 2 & 0 & 16,2 & 108,0 & 1,20 & 1,640 \\
\hline
\end{tabular}

${ }^{a}$ Constant $(0,1,2 \ldots, \mathrm{n})$ used in Eq. 2.2.a

${ }^{b}$ Numerical coefficients which is fitted to experimental data used in Eq. 2.2.a

${ }^{c}$ Certain multipliers for special refrigerant used in Eq. 2.2.a

${ }^{d}$ Certain upper coefficients for special refrigerant used in Eq. 2.2.a 
Table 3. Composition of R410A

\begin{tabular}{|c|c|c|c|}
\hline $\mathrm{i}$ & Component & Mass Fraction & Mole Fraction \\
\hline 1 & $\mathrm{R} 32$ & 0,50 & 0,69761470 \\
\hline 2 & $\mathrm{R} 125$ & 0,50 & 0,30238530 \\
\hline
\end{tabular}

Table 4. Coefficient and exponents of the excess functions for R410A [Equation (2.12)]

\begin{tabular}{|c|c|c|c|c|}
\hline & R32/125 Binary Pair ${ }^{\mathrm{a}}$ & & & \\
\hline$k$ & $N_{k}$ & $t_{k}$ & $d_{k}$ & $l_{k}$ \\
\hline 1 & $-0,0072955$ & 4,50 & 2 & 1 \\
\hline 2 & 0,078035 & 0,57 & 5 & 1 \\
\hline 3 & 0,61007 & 1,90 & 1 & 2 \\
\hline 4 & 0,64246 & 1,20 & 3 & 2 \\
\hline 5 & 0,014965 & 0,50 & 9 & 2 \\
\hline 6 & $-0,34049$ & 2,60 & 2 & 3 \\
\hline 7 & 0,085658 & 11,40 & 3 & 3 \\
\hline 8 & $-0,064429$ & 4,50 & 6 & 3 \\
\hline
\end{tabular}

In order to give a quantitative principle for selecting a suitable reference state, case study at the sensitivity of temperature difference between the reference state and the critical point on the prediction effects were needed. In all thermodynamic property calculations for superheated region of R1234yf, reference state parameters and its coefficients were taken as fallow: $T_{r e f}=273,15 \mathrm{~K}, P_{r e f}=1,0 \mathrm{kPa}$, $f_{l}=-12,837928, f_{2}=8,042605$. Also, the reference states, $\mathrm{h}_{\mathrm{ref}}$ and $\mathrm{s}_{\mathrm{ref}}$ were chosen to yield a reference state for enthalpy of $200 \mathrm{~kJ} \cdot \mathrm{kg}^{-1}$ and for entropy of $1 \mathrm{~kJ}^{\mathrm{k}} \mathrm{kg}^{-1} \mathrm{~K}^{-1}$, both for the saturated liquid at $0{ }^{0} \mathrm{C}$.

Accordingly, Coefficient values of R410A refrigerant mixture were given in table 3 and table 4 for superheated and saturated thermal properties, as an ideal and real gas. These coefficients are valid within the following ranges: $T_{\min }=$ $172,52 \mathrm{~K}, T_{\max }=435 \mathrm{~K}, P_{\max }=60 \mathrm{MPa}, \rho_{\max }=20,2 \mathrm{~mol} \mathrm{l}^{-1}$ $\left(1496 \mathrm{~kg} \mathrm{~m}^{-3}\right)$. In order to ensure the accuracy of the new program, all the coefficients were in the format of double precision in programming and so have long digits. An equation of state for refrigerant mixture may express the reduced molar Helmholtz energy, as a function of temperature and density. In equation of states, critical parameters and physical properties of R410A( based on its composition(R32 \& R125)) were used for reducing molar Helmholtz energy. Reducing Parameters, molar mass and gas constant were given as: $T^{*}=344,51 \mathrm{~K}, \rho^{*}=459,5 \mathrm{~kg} \mathrm{~m}^{-3}$, $M=72,5855 \mathrm{~g}(\mathrm{~mol})^{-1}, R=8,314471 \mathrm{~J}(\mathrm{~mol} . \mathrm{K})^{-1}$.

In order to give a quantitative principle for selecting a suitable reference state, case study at the sensitivity of temperature difference between the reference state and the critical point on the prediction effects were needed. In all thermodynamic property calculations for superheated region of R410A, reference state parameters and its coefficients were taken as fallow: $T_{r e f}=273,15 \mathrm{~K}, P_{r e f}=1,0 \mathrm{kPa}$, $f_{3}=0,617469323, f_{4}=-0,596795$, $\zeta_{12}=28,95, \xi_{12}=-0,006008, F_{12}=1,00$

\subsection{Accuracy Assessment of Developed Computer Program}

Statistical analyses are used for determining the overall estimated accuracy of the model, and defining the ranges of estimated uncertainties due to the various properties calculated with the program.

The statistics used for evaluating the equation were based on the percent (absolute) deviation for any property, $X$,

$$
\% \Delta \mathrm{X}=\left[\left(\mathrm{X}_{\text {data }}-\mathrm{X}_{\text {calc }}\right) / \mathrm{X}_{\text {data }}\right] .100
$$

Using this definition, the average absolute deviation (Mean deviation) was defined as

$$
M D=\frac{1}{n} \sum_{i=1}^{n}(\% \Delta X)
$$

Where $n$ is the number of data points. The uncertainties of calculated values of various properties for the R1234yf and R410A refrigerant regions were predicted to have a clear demonstration of the accuracy of the proposed program, sensitivity of thermal properties by comparisons with REFPROP values. The obtained thermodynamic properties from the developed program were compared to the REFPROP data by the use of the mean and absolute deviation as given by Eq. (4.1) (4.2). Under the prediction range (for superheated region of R1234yf, temperature in $233 \mathrm{~K}$ and $448 \mathrm{~K}$, for subcooled region, temperature in $238 \mathrm{~K}$ and $410 \mathrm{~K}$, for saturated region, $230 \mathrm{~K}$ and $360 \mathrm{~K}$, pressure in 0,05-3 MPa for three regions. Similarly, for superheated region of R410A, temperature in $185 \mathrm{~K}$ and $460 \mathrm{~K}$, pressure in $0,01-1,5 \mathrm{MPa}$, for subcooled region, temperature in $184 \mathrm{~K}$ and $333 \mathrm{~K}$, pressure in $0,01-4,9 \mathrm{MPa}$, for saturated region, 
temperature in $185 \mathrm{~K}$ and $345 \mathrm{~K}$, pressure in 0,01-4,9 MPa). we ran the developed computer program for R1234yf when the temperature data were separated into temperature increments of $5 \mathrm{~K}$ and for R410A when the temperature data were seperated into temperature increments of $5 \mathrm{~K}$ in subcooled and saturated regions, $10 \mathrm{~K}$ in superheated region.

The comparisons of the developed program to REFPROP data exhibit many general trends, as shown in the tables presented in this study. Summary comparisons of values calculated using the programs to data for $\rho-h-s$, density, specific enthalpy and specific entropy for R1234yf and R410A refrigerants were given in Tables $(5,6,7,8,9,10,11,12)$, along with the temperature range of the data.

\subsubsection{Superheated and Sub Cooled Refrigerant Thermal Properties}

In most of refrigeration simulations that involve superheated refrigerant states, the temperature was usually considered as an input parameter. The thermal properties of most interest are: pressure, specific enthalpy, specific entropy, and density. When each of them are known in conjunction with the temperature, the other three can be determined. Consequently, it should be noted that when the value of the pressure and temperature are given as a fixed data, then the calculated specific enthalpy, entropy and density show all monotonic trends with temperature.

Discussions of maximum errors or of systematic offsets always use the absolute values of the deviations. Table 5(superheated), table 7(subcooled) for R410A and table 6(superheated), table 8(subcooled) for R1234yf showed the absolute deviations of the calculated properties with those from REFPROP 9.0. Also, a review of the results of Table 5 revealed that; the maximum absolute deviations for the density were almost $0,16555 \%$ at $215 \mathrm{~K}$, the maximum absolute deviations for the specific enthalpy were almost $0,038 \%$ at $185 \mathrm{~K}$, and the maximum absolute deviations for the specific entropy were almost $0,0399 \%$ at $460 \mathrm{~K}$ in superheated region for R410A refrigerant. Similarly, a review of the results of Table 6 revealed that; the maximum absolute deviations for the density were almost $0,4457 \%$ at $423 \mathrm{~K}$, the maximum absolute deviations for the specific enthalpy were almost $0,410 \%$ at $448 \mathrm{~K}$, and the maximum absolute deviations for the specific entropy were almost $0,3193 \%$ at $408 \mathrm{~K}$ in superheated region for R1234yf refrigerant. The maximum absolute deviations for the density were almost $0,08187 \%$ at $290 \mathrm{~K}$, the maximum absolute deviations for the specific enthalpy were almost $0,2583 \%$ at $215 \mathrm{~K}$ and the maximum absolute deviations for the specific entropy were almost $0,0807 \%$ at $295 \mathrm{~K}$ in subcooled region for R410A refrigerant. Similarly, the maximum absolute deviations for the density were almost $0,4553 \%$ at $408 \mathrm{~K}$, the maximum absolute deviations for the specific enthalpy were almost $0,4221 \%$ at $393 \mathrm{~K}$ and the maximum absolute deviations for the specific entropy were almost $0,3887 \%$ at $408 \mathrm{~K}$ in subcooled region for R1234yf refrigerant.

The mean deviations of the calculated thermal properties of R1234yf and R410A for the superheated and subcooled regions were made comparison with REFPROP 9.0, and all the mean deviation of R1234yf and R410A thermal properties $(\rho, h$ and $s)$ collected in the same tables. The mean deviations (uncertainties) in the calculation of thermodynamic properties were: $0,21957 \%$ in density, $0,1906 \%$ in specific enthalpy and $0,1461 \%$ in specific entropy for R1234yf refrigerant, accordingly, $0,0232 \%$ in density, $0,0132 \%$ in specific enthalpy and $0,0203 \%$ in specific entropy for R410A refrigerant in the superheated region. It can be seen that the mean deviations of the calculated enthalpy, entropy and specific volume were acceptable and lower than $0.5 \%$. Similar results were also found for thermal properties of R1234yf and R410A in subcooled region. 
Table 5. Predicting of thermodynamic properties(Helmholtz Equation of State was utilized) and deviations for R410A refrigerant in superheated region

\begin{tabular}{|c|c|c|c|c|c|c|c|c|c|c|}
\hline $\mathrm{T}(\mathrm{K})$ & $\mathrm{P}(\mathrm{MPa})$ & $\begin{array}{l}\text { REFPROP } \\
\text { 9.0Estimated } \\
\text { Values for } \\
\rho(\text { kgm-3) }\end{array}$ & $\begin{array}{c}\text { REF ISO17584 } \\
\text { Estimated } \\
\text { Values for } \\
\rho(\mathrm{kgm}-3)\end{array}$ & Mean Deviation (\%) & $\begin{array}{c}\text { REFPROP } 9.0 \\
\text { Estimated } \\
\text { Values for } \\
\mathrm{h}(\mathrm{kjkg}-1)\end{array}$ & $\begin{array}{c}\text { REF } \\
\text { ISO17584 } \\
\text { Estimated } \\
\text { Values for } \\
\text { h(kjkg-1) }\end{array}$ & Mean Deviation (\%) & $\begin{array}{l}\text { REFPROP } 9.0 \\
\text { Estimated Values } \\
\text { for s(kjkg-1K-1) }\end{array}$ & $\begin{array}{l}\text { REF ISO17584 } \\
\text { Estimated Values } \\
\text { for s(kjkg-1K-1) }\end{array}$ & $\begin{array}{c}\text { Mean Deviation } \\
(\%)\end{array}$ \\
\hline 85 & 0,01 & 0,54353 & 0,54356 & 0,00551917 & 341,43 & 341,56 & 0,038060663 & 1,8909 & 1,8912 & 0,015862944 \\
\hline 195 & 0,015 & 0,67917 & 0,67924 & 0,010305636 & 385,05 & 385,18 & 0,033750454 & 2,0798 & 2,0801 & 0,014422384 \\
\hline 205 & 0,02 & 0,86194 & 0,86198 & 0,004640479 & 391,58 & 391,64 & 0,015320192 & 2,0799 & 2,0803 & 0,019227996 \\
\hline 215 & 0,03 & 1,236 & 1,238 & 0,161550889 & 398,04 & 398,09 & 0,012559974 & 2,0649 & 2,0653 & 0,019367646 \\
\hline 225 & 0,04 & 1,5769 & 1,5774 & 0,03169773 & 404,77 & 404,82 & 0,012351168 & 2,063 & 2,0634 & 0,01938548 \\
\hline 235 & 0,05 & 1,8885 & 1,889 & 0,026469031 & 411,71 & 411,76 & 0,012142996 & 2,068 & 2,0684 & 0,019338619 \\
\hline 245 & 0,06 & 2,1742 & 2,1745 & 0,013796275 & 418,85 & 418,91 & 0,014322886 & 2,0772 & 2,0775 & 0,014440433 \\
\hline 255 & 0,07 & 2,4368 & 2,4372 & 0,016412276 & 426,16 & 426,18 & 0,004692853 & 2,0891 & 2,0896 & 0,023928025 \\
\hline 265 & 0,08 & 2,679 & 2,6796 & 0,022391402 & 433,65 & 433,69 & 0,009223178 & 2,1028 & 2,103 & 0,009510223 \\
\hline 273 & 0,09 & 2,9257 & 2,9261 & 0,013670073 & 439,7 & 439,73 & 0,006822368 & 2,1121 & 2,1124 & 0,014201856 \\
\hline 275 & 0,1 & 3,2315 & 3,2319 & 0,012376621 & 441,07 & 441,12 & 0,011334784 & 2,1052 & 2,1056 & 0,01899696 \\
\hline 285 & 0,12 & 3,745 & 3,7456 & 0,016018795 & 448,71 & 448,74 & 0,006685386 & 2,112 & 2,1124 & 0,018935808 \\
\hline 295 & 0,14 & 4,2231 & 4,2234 & 0,007103282 & 456,53 & 456,56 & 0,006570878 & 2,1216 & 2,122 & 0,018850141 \\
\hline 305 & 0,16 & 4,6691 & 4,6695 & 0,008566228 & 464,54 & 464,58 & 0,008609927 & 2,1333 & 2,1339 & 0,028117531 \\
\hline 315 & 0,18 & 5,0858 & 5,0861 & 0,005898429 & 472,72 & 472,75 & 0,006345849 & 2,1465 & 2,1468 & 0,013974287 \\
\hline 325 & 0,2 & 5,4761 & 5,4764 & 0,005478051 & 481,07 & 481,12 & 0,010392418 & 2,1607 & 2,161 & 0,013882462 \\
\hline 335 & 0,25 & 6,6563 & 6,6565 & 0,003004582 & 489,23 & 489,28 & 0,010219097 & 2,1604 & 2,1608 & 0,018511662 \\
\hline 345 & 0,3 & 7,7693 & 7,7696 & 0,003861203 & 497,61 & 497,65 & 0,008037778 & 2,1646 & 2,1648 & 0,009238729 \\
\hline 355 & 0,35 & 8,8196 & 8,8201 & 0,00566887 & 506,19 & 506,24 & 0,009876738 & 2,1719 & 2,1724 & 0,023016019 \\
\hline 365 & 0,4 & 9,8114 & 9,8118 & 0,004076724 & 514,97 & 515,01 & 0,007766839 & 2,1814 & 2,1818 & 0,018333486 \\
\hline 375 & 0,45 & 10,749 & 10,7496 & 0,005581603 & 523,94 & 523,99 & 0,009542167 & 2,1925 & 2,1928 & 0,013681138 \\
\hline 385 & 0,5 & 11,635 & 11,64 & 0,042955326 & 533,08 & 533,13 & 0,009378576 & 2,2048 & 2,2052 & 0,018138944 \\
\hline 395 & 0,6 & 13,642 & 13,645 & 0,021986075 & 542,01 & 542,06 & 0,009224071 & 2,2073 & 2,2075 & 0,009060023 \\
\hline 405 & 0,7 & 15,55 & 15,556 & 0,038570327 & 551,15 & 551,28 & 0,023581483 & 2,213 & 2,2136 & 0,027105168 \\
\hline 415 & 0,8 & 17,366 & 17,372 & 0,034538338 & 560,49 & 560,58 & 0,0160548 & 2,221 & 2,2218 & 0,036006841 \\
\hline 425 & 0,9 & 19,093 & 19,099 & 0,031415257 & 570,03 & 570,12 & 0,01578615 & 2,2306 & 2,2312 & 0,026891359 \\
\hline 435 & 1 & 20,737 & 20,744 & 0,033744697 & 579,75 & 579,84 & 0,015521523 & 2,2416 & 2,2424 & 0,035676061 \\
\hline 445 & 1,2 & 24,404 & 24,412 & 0,032770768 & 589,05 & 589,16 & 0,01867065 & 2,2425 & 2,2432 & 0,031205421 \\
\hline 455 & 1,4 & 27,914 & 27,924 & 0,035811488 & 598,59 & 598,68 & 0,015033073 & 2,2467 & 2,2472 & 0,022249911 \\
\hline 460 & 1,5 & 29,612 & 29,624 & 0,040507696 & 603,44 & 603,56 & 0,019882033 & 2,2497 & 2,2506 & 0,039989336 \\
\hline
\end{tabular}


Table 6. Predicting of thermodynamic properties (Helmholtz Equation of State was utilized) and deviations for R1234yf refrigerant in superheated region

\begin{tabular}{|c|c|c|c|c|c|c|c|c|c|c|}
\hline $\mathrm{T}(\mathrm{K})$ & $\mathrm{P}(\mathrm{MPa})$ & $\begin{array}{c}\text { REFPROP } 9.0 \\
\text { Estimated } \\
\text { Values for } \\
\rho(\mathrm{kgm}-3)\end{array}$ & $\begin{array}{c}\text { REF ISO17584 } \\
\text { Estimated } \\
\text { Values for } \\
\rho(\mathrm{kgm}-3) \\
\end{array}$ & $\begin{array}{c}\text { Mean Deviation } \\
(\%)\end{array}$ & $\begin{array}{l}\text { REFPROP } 9.0 \\
\text { Estimated Values } \\
\text { for h(kjkg-1) }\end{array}$ & $\begin{array}{c}\text { REF ISO17584 } \\
\text { Estimated } \\
\text { Values for } \\
\mathrm{h}(\mathrm{kjkg}-1)\end{array}$ & $\begin{array}{c}\text { Mean Deviation } \\
(\%)\end{array}$ & $\begin{array}{l}\text { REFPROP 9.0 } \\
\text { Estimated Values } \\
\text { for s(kjkg-1K-1) }\end{array}$ & $\begin{array}{c}\text { REF ISO17584 } \\
\text { Estimated Values for } \\
\text { s(kjkg-1K-1) }\end{array}$ & $\begin{array}{c}\text { Mean Deviation } \\
(\%)\end{array}$ \\
\hline 233 & 0,05 & 3,021148036 & 3,02091 & 0,007879 & 337 & 337,17 & 0,05041967 & 1,62 & 1,6212 & 0,074019245 \\
\hline 238 & 0,055 & 3,255208333 & 3,25481 & 0,0122368 & 340,7 & 340,91 & 0,061599836 & 1,63 & 1,6303 & 0,018401521 \\
\hline 243 & 0,06 & 3,47947112 & 3,47874 & 0,0210124 & 344,5 & 344,72 & 0,063819912 & 1,639 & 1,6399 & 0,054881395 \\
\hline 248 & 0,065 & 3,694126339 & 3,69365 & 0,0128945 & 348,4 & 348,6 & 0,057372347 & 1,649 & 1,65 & 0,060606061 \\
\hline 253 & 0,07 & 3,900156006 & 3,89962 & 0,0137432 & 352,3 & 352,54 & 0,068077381 & 1,66 & 1,6605 & 0,030111412 \\
\hline 258 & 0,075 & 4,096681688 & 4,09613 & 0,0134667 & 356,3 & 356,54 & 0,067313625 & 1,67 & 1,6712 & 0,071804691 \\
\hline 263 & 0,08 & 4,286326618 & 4,28526 & 0,0248842 & 360,3 & 360,6 & 0,083194676 & 1,681 & 1,6822 & 0,071335156 \\
\hline 268 & 0,09 & 4,739336493 & 4,73899 & 0,007311 & 364,3 & 364,62 & 0,087762602 & 1,688 & 1,6889 & 0,053289123 \\
\hline 273 & 0,1 & 5,175983437 & 5,17498 & 0,0193864 & 368,4 & 368,7 & 0,081366965 & 1,695 & 1,6966 & 0,09430626 \\
\hline 278 & 0,101325 & 5,141388175 & 5,14045 & 0,0182475 & 372,7 & 373 & 0,080428954 & 1,71 & 1,7112 & 0,070126227 \\
\hline 283 & 0,11 & 5,488474204 & 5,48742 & 0,0192076 & 376,9 & 377,23 & 0,087479787 & 1,719 & 1,7204 & 0,081376424 \\
\hline 288 & 0,12 & 5,885815185 & 5,88488 & 0,0158888 & 381,1 & 381,49 & 0,102230727 & 1,728 & 1,7292 & 0,069396253 \\
\hline 293 & 0,13 & 6,273525721 & 6,26996 & 0,0568376 & 385,4 & 385,81 & 0,106269926 & 1,737 & 1,7383 & 0,07478571 \\
\hline 298 & 0,14 & 6,644518272 & 6,63566 & 0,133317 & 389,8 & 390,19 & 0,099951306 & 1,747 & 1,7479 & 0,05149036 \\
\hline 303 & 0,15 & 7,00280112 & 6,99196 & 0,1548112 & 394,2 & 394,62 & 0,106431504 & 1,756 & 1,7577 & 0,096717301 \\
\hline 308 & 0,16 & 7,352941176 & 7,33696 & 0,217344 & 398,7 & 399,11 & 0,102728571 & 1,766 & 1,7678 & 0,101821473 \\
\hline 313 & 0,17 & 7,686395081 & 7,66964 & 0,2179836 & 403,2 & 403,65 & 0,11148272 & 1,777 & 1,7782 & 0,067483973 \\
\hline 318 & 0,18 & 8,012820513 & 7,99674 & 0,2006848 & 407,8 & 408,24 & 0,107779737 & 1,787 & 1,7886 & 0,08945544 \\
\hline 323 & 0,19 & 8,326394671 & 8,30864 & 0,2132336 & 412,4 & 412,88 & 0,116256539 & 1,798 & 1,7993 & 0,07225032 \\
\hline 328 & 0,2 & 8,628127696 & 8,60875 & 0,2245875 & 417,1 & 417,57 & 0,112555979 & 1,809 & 1,81 & 0,055248619 \\
\hline 333 & 0,22 & 9,36329588 & 9,34377 & 0,2085364 & 421,7 & 422,21 & 0,12079297 & 1,816 & 1,8173 & 0,071534694 \\
\hline
\end{tabular}




\begin{tabular}{|c|c|c|c|c|c|c|c|c|c|c|}
\hline 338 & 0,24 & 10,08064516 & 10,06261 & 0,1789088 & 426,3 & 426,9 & 0,140548138 & 1,824 & 1,8251 & 0,06027067 \\
\hline 343 & 0,26 & 10,77586207 & 10,753111 & 0,21112992 & 431,1 & 431,65 & 0,127418047 & 1,832 & 1,8334 & 0,07636086 \\
\hline 348 & 0,28 & 11,4416476 & 11,418008 & 0,20661008 & 435,8 & 436,44 & 0,146641004 & 1,84 & 1,842 & 0,108577633 \\
\hline 353 & 0,3 & 12,09189843 & 12,06096 & 0,2558608 & 440,6 & 441,29 & 0,156359763 & 1,849 & 1,851 & 0,108049703 \\
\hline 358 & 0,35 & 13,98601399 & 13,95056 & 0,253496 & 445,2 & 445,93 & 0,163702823 & 1,851 & 1,8532 & 0,118713577 \\
\hline 363 & 0,4 & 15,82278481 & 15,78118 & 0,2629424 & 449,8 & 450,64 & 0,186401562 & 1,855 & 1,8569 & 0,102321073 \\
\hline 368 & 0,45 & 17,6056338 & 17,55132 & 0,3085024 & 454,5 & 455,41 & 0,199819942 & 1,859 & 1,8617 & 0,145028737 \\
\hline 373 & 0,5 & 19,37984496 & 19,32462 & 0,2849608 & 459,2 & 460,23 & 0,223801143 & 1,865 & 1,8674 & 0,128520938 \\
\hline 378 & 0,6 & 23,14814815 & 23,08035 & 0,292888 & 463,5 & 464,73 & 0,264669808 & 1,864 & 1,8668 & 0,149989286 \\
\hline 383 & 0,7 & 26,80965147 & 26,72637 & 0,3106399 & 467,9 & 469,31 & 0,300441073 & 1,865 & 1,8682 & 0,171287871 \\
\hline 388 & 0,8 & 30,48780488 & 30,38783 & 0,3279176 & 472,4 & 473,95 & 0,327038717 & 1,867 & 1,8711 & 0,219122441 \\
\hline 393 & 0,9 & 34,01360544 & 33,88708 & 0,3719848 & 477 & 478,66 & 0,346801487 & 1,871 & 1,8752 & 0,223976109 \\
\hline 398 & 1 & 37,59398496 & 37,45318352 & 0,374531835 & 481,6 & 483,18 & 0,32700029 & 1,876 & 1,881 & 0,265816055 \\
\hline 403 & 1,2 & 45,04504505 & 44,86316734 & 0,403768506 & 485,4 & 487,18 & 0,365368036 & 1,873 & 1,878 & 0,266240682 \\
\hline 408 & 1,4 & 52,63157895 & 52,41090147 & 0,419287212 & 489,3 & 490,65 & 0,275145216 & 1,873 & 1,879 & 0,319318787 \\
\hline 413 & 1,6 & 60,24096386 & 60,0240096 & 0,360144058 & 493,4 & 494,81 & 0,284957863 & 1,874 & 1,88 & 0,319148936 \\
\hline 418 & 1,8 & 67,56756757 & 67,29475101 & 0,403768506 & 497,5 & 498,96 & 0,292608626 & 1,876 & 1,882 & 0,318809777 \\
\hline 423 & 2 & 74,62686567 & 74,29420505 & 0,44576523 & 501,7 & 503,72 & 0,401016438 & 1,879 & 1,885 & 0,318302387 \\
\hline 428 & 2,2 & 81,96721311 & 81,63265306 & 0,408163265 & 506,1 & 508,12 & 0,397543887 & 1,884 & 1,89 & 0,317460317 \\
\hline 433 & 2,4 & 89,28571429 & 88,88888889 & 0,444444444 & 510,5 & 512,56 & 0,401904167 & 1,889 & 1,895 & 0,316622691 \\
\hline 438 & 2,6 & 96,15384615 & 95,6937799 & 0,4784689 & 515 & 516,96 & 0,379139585 & 1,894 & 1,9 & 0,315789474 \\
\hline 443 & 2,8 & 103,0927835 & 102,6694045 & 0,410677618 & 519,7 & 521,76 & 0,394817541 & 1,9 & 1,906 & 0,314795383 \\
\hline 448 & 3 & 108,6956522 & 108,2251082 & 0,432900433 & 524,4 & 526,56 & 0,410209663 & 1,906 & 1,912 & 0,313807531 \\
\hline
\end{tabular}


Table 7. Predicting of thermodynamic properties (Helmholtz Equation of State was utilized) and deviations for R410A refrigerant in subcooled region

\begin{tabular}{|c|c|c|c|c|c|c|c|c|c|c|}
\hline $\mathrm{T}(\mathrm{K})$ & $\mathrm{P}(\mathrm{MPa})$ & $\begin{array}{c}\text { REFPROP } 9.0 \\
\text { Estimated } \\
\text { Values for } \\
\rho(\mathrm{kgm}-3)\end{array}$ & $\begin{array}{l}\text { REF ISO17584 } \\
\text { Estimated Values } \\
\text { for } \rho(\mathrm{kgm}-3)\end{array}$ & $\begin{array}{c}\text { Mean Deviation } \\
(\%)\end{array}$ & $\begin{array}{c}\text { REFPROP } 9.0 \\
\text { Estimated } \\
\text { Values for } \\
\text { h(kjkg-1) }\end{array}$ & $\begin{array}{l}\text { REF ISO17584 } \\
\text { Estimated Values } \\
\text { for } \mathrm{h}(\mathrm{kjkg}-1)\end{array}$ & $\begin{array}{c}\text { Mean Deviation } \\
(\%)\end{array}$ & $\begin{array}{c}\text { REFPROP } 9.0 \\
\text { Estimated Values } \\
\text { for s(kjkg-1K-1) }\end{array}$ & $\begin{array}{c}\text { REF ISO17584 } \\
\text { Estimated Values } \\
\text { for s(kjkg-1K-1) }\end{array}$ & $\begin{array}{c}\text { Mean } \\
\text { Deviation (\%) }\end{array}$ \\
\hline 185 & 0,01 & 1463,3 & 1463,8 & 0,034157672 & 75,321 & 75,4 & 0,104774536 & 0,45212 & 0,45218 & 0,013269052 \\
\hline 190 & 0,015 & 1445,8 & 1446,4 & 0,041482301 & 83,388 & 83,48 & 0,110206037 & 0,49525 & 0,49536 & 0,022206072 \\
\hline 195 & 0,02 & 1434 & 1434,5 & 0,03485535 & 88,769 & 88,96 & 0,214703237 & 0,52326 & 0,52334 & 0,015286429 \\
\hline 200 & 0,03 & 1416,2 & 1416,8 & 0,042348955 & 96,853 & 96,88 & 0,027869529 & 0,56426 & 0,56434 & 0,014175851 \\
\hline 205 & 0,04 & 1404,2 & 1404,6 & 0,028477858 & 102,25 & 102,45 & 0,195217179 & 0,59096 & 0,59102 & 0,010151941 \\
\hline 210 & 0,06 & 1386 & 1386,8 & 0,057686761 & 110,38 & 110,6 & 0,198915009 & 0,63016 & 0,63024 & 0,012693577 \\
\hline 215 & 0,08 & 1373,7 & 1374,2 & 0,036384806 & 115,82 & 116,12 & 0,258353427 & 0,65574 & 0,65584 & 0,015247621 \\
\hline 220 & 0,1 & 1355,1 & 1355,6 & 0,036884037 & 124,01 & 124,24 & 0,185125563 & 0,69341 & 0,69345 & 0,00576826 \\
\hline 225 & 0,12 & 1342,5 & 1343,2 & 0,052114354 & 129,5 & 129,8 & 0,231124807 & 0,71806 & 0,71814 & 0,011139889 \\
\hline 230 & 0,16 & 1323,3 & 1324,2 & 0,067965564 & 137,78 & 138,02 & 0,173887842 & 0,75441 & 0,75448 & 0,009277913 \\
\hline 235 & 0,2 & 1310,3 & 1310,9 & 0,045770082 & 143,33 & 143,48 & 0,104544187 & 0,77824 & 0,77832 & 0,010278549 \\
\hline 240 & 0,25 & 1290,4 & 1291 & 0,0464756 & 151,73 & 152,01 & 0,184198408 & 0,8135 & 0,81356 & 0,007374994 \\
\hline 245 & 0,3 & 1277 & 1277,5 & 0,039138943 & 157,37 & 157,48 & 0,06985014 & 0,83667 & 0,83672 & 0,005975715 \\
\hline 250 & 0,4 & 1256,4 & 1256,8 & 0,031826862 & 165,92 & 166,22 & 0,180483696 & 0,87096 & 0,87104 & 0,009184423 \\
\hline 255 & 0,5 & 1242,4 & 1243 & 0,048270314 & 171,68 & 172,02 & 0,197651436 & 0,8935 & 0,89354 & 0,004476576 \\
\hline 260 & 0,6 & 1220,7 & 1221,3 & 0,049127978 & 180,41 & 180,56 & 0,083074878 & 0,92712 & 0,92718 & 0,006471235 \\
\hline 265 & 0,7 & 1206 & 1206,8 & 0,066291018 & 186,29 & 186,54 & 0,134019513 & 0,94928 & 0,94934 & 0,00632018 \\
\hline 270 & 0,8 & 1182,8 & 1183,4 & 0,050701369 & 195,24 & 195,64 & 0,204457166 & 0,98248 & 0,98254 & 0,006106622 \\
\hline 273 & 0,9 & 1171,1 & 1171,6 & 0,042676681 & 199,78 & 200,02 & 0,119988001 & 0,99887 & 0,99894 & 0,007007428 \\
\hline 280 & 1 & 1141,9 & 1142,5 & 0,052516411 & 210,53 & 210,84 & 0,147030924 & 1,0375 & 1,038 & 0,048169557 \\
\hline 285 & 1,2 & 1125,3 & 1125,9 & 0,053290701 & 216,79 & 216,99 & 0,092170146 & 1,059 & 1,0596 & 0,056625142 \\
\hline 290 & 1,4 & 1098,4 & 1099,3 & 0,081870281 & 226,38 & 226,56 & 0,079449153 & 1,0918 & 1,0924 & 0,054924936 \\
\hline 295 & 1,6 & 1080,1 & 1080,8 & 0,064766839 & 232,9 & 233,24 & 0,145772595 & 1,1135 & 1,1144 & 0,080760948 \\
\hline 300 & 1,8 & 1049,9 & 1050,6 & 0,066628593 & 242,96 & 243,12 & 0,065811122 & 1,1468 & 1,1476 & 0,069710701 \\
\hline 305 & 2 & 1029 & 1029,8 & 0,077684987 & 249,83 & 250,06 & 0,091977925 & 1,1689 & 1,1694 & 0,042756969 \\
\hline 310 & 2,5 & 998,17 & 998,24 & 0,007012342 & 260,28 & 260,54 & 0,099792738 & 1,2013 & 1,202 & 0,058236273 \\
\hline 315 & 3 & 979,05 & 979,3 & 0,025528439 & 267,22 & 267,34 & 0,044886661 & 1,2219 & 1,2226 & 0,05725503 \\
\hline 320 & 3,5 & 944,44 & 944,64 & 0,021172087 & 278,24 & 278,36 & 0,043109642 & 1,255 & 1,2558 & 0,063704412 \\
\hline 325 & 4 & 923,41 & 923,91 & 0,054117825 & 285,5 & 285,64 & 0,049012743 & 1,2759 & 1,2765 & 0,047003525 \\
\hline 330 & 4,5 & 883,44 & 883,74 & 0,033946636 & 297,31 & 297,52 & 0,07058349 & 1,3103 & 1,3112 & 0,068639414 \\
\hline 333 & 4,9 & 866,71 & 866,94 & 0,026530094 & 302,97 & 303,12 & 0,049485352 & 1,326 & 1,3265 & 0,037693178 \\
\hline
\end{tabular}


Table 8. Predicting of thermodynamic properties(Helmholtz Equation of State was utilized) and deviations for R1234yf refrigerant in subcooled region

\begin{tabular}{|c|c|c|c|c|c|c|c|c|c|c|}
\hline $\mathrm{T}(\mathrm{K})$ & $\mathrm{P}(\mathrm{MPa})$ & $\begin{array}{l}\text { REFPROP } 9.0 \text { Estimated } \\
\text { Values for } \rho(\mathrm{kgm}-3)\end{array}$ & $\begin{array}{c}\text { REF ISO17584 } \\
\text { Estimated Values for } \\
\rho(\mathrm{kgm}-3)\end{array}$ & $\begin{array}{c}\text { Mean } \\
\text { Deviation (\%) }\end{array}$ & $\begin{array}{l}\text { REFPROP 9.0 } \\
\text { Estimated Values } \\
\text { for h(kjkg-1) }\end{array}$ & $\begin{array}{c}\text { REF ISO17584 } \\
\text { Estimated Values for } \\
\mathrm{h}(\mathrm{kjkg}-1)\end{array}$ & $\begin{array}{c}\text { Mean Deviation } \\
(\%)\end{array}$ & $\begin{array}{l}\text { REFPROP } 9.0 \\
\text { Estimated Values } \\
\text { for s(kjkg-1K-1) }\end{array}$ & $\begin{array}{l}\text { REF ISO17584 } \\
\text { Estimated Values } \\
\text { for s(kjkg-1K-1) }\end{array}$ & $\begin{array}{c}\text { Mean } \\
\text { Deviation (\%) }\end{array}$ \\
\hline 238 & 0,05 & 2,9535 & 2,9538 & 0,010156409 & 177,34 & 177,41 & 0,039456626 & 0,7774 & 0,7775 & 0,012861736 \\
\hline 243 & 0,055 & 3,1836 & 3,184 & 0,012562814 & 181,13 & 181,24 & 0,060693004 & 0,78636 & 0,78646 & 0,012715205 \\
\hline 248 & 0,06 & 3,4042 & 3,4044 & 0,00587475 & 184,98 & 185,16 & 0,097213221 & 0,79586 & 0,79594 & 0,010051009 \\
\hline 253 & 0,065 & 3,6158 & 3,6161 & 0,008296231 & 188,89 & 189,03 & 0,074062318 & 0,8058 & 0,806 & 0,024813896 \\
\hline 258 & 0,07 & 3,8188 & 3,8192 & 0,010473398 & 192,87 & 193,02 & 0,077712154 & 0,8161 & 0,8164 & 0,036746693 \\
\hline 263 & 0,075 & 4,0138 & 4,0141 & 0,007473655 & 196,91 & 197,08 & 0,086259387 & 0,82669 & 0,8271 & 0,04957079 \\
\hline 268 & 0,08 & 4,2012 & 4,2016 & 0,009520183 & 201 & 201,24 & 0,119260584 & 0,83754 & 0,83772 & 0,021486893 \\
\hline 273 & 0,09 & 4,6465 & 4,647 & 0,01075963 & 205,05 & 205,29 & 0,116907789 & 0,84413 & 0,84445 & 0,037894488 \\
\hline 278 & 0,1 & 5,0759 & 5,0764 & 0,0098495 & 209,16 & 209,37 & 0,100300903 & 0,85158 & 0,85216 & 0,068062336 \\
\hline 283 & 0,12 & 6,0061 & 6,0065 & 0,006659452 & 213,14 & 213,36 & 0,103112111 & 0,85287 & 0,85324 & 0,043364118 \\
\hline 288 & 0,14 & 6,9081 & 6,9086 & 0,007237356 & 217,2 & 217,46 & 0,119562218 & 0,85622 & 0,85674 & 0,060695193 \\
\hline 293 & 0,16 & 7,7823 & 7,7829 & 0,007709209 & 221,33 & 221,65 & 0,144371757 & 0,86107 & 0,86184 & 0,08934373 \\
\hline 298 & 0,18 & 8,6293 & 8,6298 & 0,005793877 & 225,54 & 225,88 & 0,150522401 & 0,86705 & 0,86745 & 0,046112168 \\
\hline 303 & 0,2 & 9,4497 & 9,4501 & 0,004232759 & 229,81 & 230,21 & 0,173754398 & 0,87392 & 0,87454 & 0,070894413 \\
\hline 308 & 0,22 & 10,244 & 10,249 & 0,048785247 & 234,16 & 234,56 & 0,17053206 & 0,88148 & 0,88196 & 0,054424237 \\
\hline 313 & 0,24 & 11,013 & 11,017 & 0,036307525 & 238,57 & 238,97 & 0,167385027 & 0,88962 & 0,89016 & 0,060663252 \\
\hline 318 & 0,26 & 11,758 & 11,763 & 0,042506163 & 243,04 & 243,48 & 0,180712995 & 0,89822 & 0,89896 & 0,082317344 \\
\hline 323 & 0,28 & 12,479 & 12,485 & 0,048057669 & 247,57 & 248,04 & 0,189485567 & 0,90721 & 0,90841 & 0,132098942 \\
\hline 328 & 0,3 & 13,178 & 13,186 & 0,060670408 & 252,16 & 252,64 & 0,189993667 & 0,91652 & 0,91756 & 0,113344086 \\
\hline 333 & 0,35 & 15,229 & 15,234 & 0,032821321 & 256,41 & 256,96 & 0,214041096 & 0,9187 & 0,92016 & 0,158668058 \\
\hline 338 & 0,4 & 17,234 & 17,241 & 0,040600893 & 260,73 & 261,24 & 0,195222784 & 0,92241 & 0,92364 & 0,133168767 \\
\hline 343 & 0,45 & 19,191 & 19,199 & 0,041668837 & 265,14 & 265,69 & 0,207008167 & 0,92727 & 0,92906 & 0,192667858 \\
\hline 348 & 0,5 & 21,1 & 21,131 & 0,146703895 & 269,62 & 270,25 & 0,233117484 & 0,93305 & 0,93452 & 0,157300004 \\
\hline 353 & 0,6 & 25,229 & 25,265 & 0,14248961 & 273,57 & 274,32 & 0,273403325 & 0,93197 & 0,93344 & 0,157482002 \\
\hline 358 & 0,7 & 29,304 & 29,342 & 0,129507191 & 277,62 & 278,52 & 0,323136579 & 0,93302 & 0,93454 & 0,162646864 \\
\hline 363 & 0,8 & 33,319 & 33,389 & 0,209649885 & 281,76 & 282,72 & 0,339558574 & 0,93565 & 0,93765 & 0,213299205 \\
\hline 368 & 0,9 & 37,266 & 37,374 & 0,288970942 & 286 & 286,96 & 0,334541399 & 0,93948 & 0,94148 & 0,212431491 \\
\hline 373 & 1 & 41,138 & 41,288 & 0,363301686 & 290,33 & 291,24 & 0,31245708 & 0,94428 & 0,94628 & 0,211353933 \\
\hline 378 & 1,2 & 49,628 & 49,814 & 0,373389007 & 293,64 & 294,64 & 0,339397231 & 0,94131 & 0,94348 & 0,229999576 \\
\hline 383 & 1,4 & 58,132 & 58,375 & 0,41627409 & 297,06 & 297,96 & 0,302053967 & 0,94053 & 0,94319 & 0,28202165 \\
\hline 388 & 1,6 & 66,617 & 66,848 & 0,345560077 & 300,61 & 301,84 & 0,407500663 & 0,9414 & 0,94434 & 0,311328547 \\
\hline 393 & 1,8 & 75,044 & 75,296 & 0,334679133 & 304,27 & 305,56 & 0,422175677 & 0,94355 & 0,94625 & 0,285336856 \\
\hline 398 & 2 & 83,38 & 83,694 & 0,375176237 & 308,07 & 309,34 & 0,410551497 & 0,94675 & 0,94996 & 0,337908965 \\
\hline 403 & 2,2 & 91,587 & 91,899 & 0,33950315 & 311,99 & 313,19 & 0,383153996 & 0,95083 & 0,95415 & 0,347953676 \\
\hline 408 & 2,5 & 104,93 & 105,41 & 0,455364766 & 314,97 & 316,26 & 0,407892241 & 0,95065 & 0,95436 & 0,388742194 \\
\hline 410 & 3 & 131,87 & 132,2 & 0,249621785 & 312,01 & 313,24 & 0,392670157 & 0,93301 & 0,93664 & 0,387555518 \\
\hline
\end{tabular}




\subsection{Two-phase and Saturated Refrigerant Thermal Properties}

For a pure refrigerant (saturated liquid and vapor) or a zeotropic mixture, two-phase thermal properties can be easily obtained from the vapor quality and liquid-vapor saturation thermal properties. Therefore, this section was only focused in the determination of two-phase refrigerant thermal properties of zeotropic mixtures. The original definition of the thermodynamic vapor quality was given by the following relation:

$$
x=\frac{m_{v}}{m_{v}+m_{l}}
$$

This definition was that used in a thermodynamic diagram. Where $x$ is the vapor quality, $m_{v}$ and $m_{l}$ are the vapor and the liquid mass, respectively. The two-phase enthalpy was given by the following relations:

$$
h_{t p}=x \cdot h_{v}+(1-x) \cdot h_{l}
$$

Where $h_{t p}$ is the two-phase enthalpy, $h_{v}$ and $h_{l}$ are the saturated vapor and the liquid enthalpies, respectively. The other properties $\rho_{t p}$ and $s_{t p}$ are found for using Eq. (4.4) in the same way.

In most of refrigeration simulations that involve two-phase refrigerant states, the temperature is usually considered as an input parameter. For saturated refrigerant thermal properties, a data set [28] with fine regular temperature spacing was used for the fitting process in this program. For predicting two-phase refrigerant thermal properties, a regular vapor saturation temperature increment of $5 \mathrm{~K}$ was used for the fitting and accuracy evaluation process, excluding saturation temperatures near the critical point. The temperature spacing varied between $230 \mathrm{~K}$ and $360 \mathrm{~K}$ for R1234yf and $210 \mathrm{~K}$ and $340 \mathrm{~K}$ for $\mathrm{R} 410 \mathrm{~A}$ depending on the section and refrigerant considered. All saturated refrigerant thermal properties were obtained from (Refrigerant) using the bubble point temperature (saturated temperature) and vapor quality as an input parameter. Bubble or dew point properties are included as $v-h-s$ data, with the bubble or dew point pressure calculated from the developed program.

Table 9, table 11 showed the results for R410A and table 10 , table 12 showed the results for R1234yf at different temperatures in the saturated liquid and vapor regions. The absolute deviations of the calculated saturated thermal properties for R1234yf and R410A were obtained to be made comparison with REFPROP 9.0, and the all absolute deviations of R1234yf and R410A thermal properties ( $\rho, h$ and $s$ ) were given separately in the tables. The mean deviations in the calculation of thermodynamic properties were: for saturated liquid $0,01257 \%$ and for saturated vapor 0,0263\% for R410A, similarly, for saturated liquid 0,0194\% and for saturated vapor $0,0183 \%$ for R1234yf in density, for saturated liquid $0,0354 \%$ and for saturated vapor $0,02395 \%$ for R410A, similarly, for saturated liquid $0,047 \%$ and for saturated vapor $0,02985 \%$ for R1234yf in specific enthalpy and for saturated liquid $0,0366 \%$ and for saturated vapor $0,0165 \%$ for R410A,similarly, for saturated liquid $0,032 \%$ and for saturated vapor $0,012 \%$ for R1234yf in specific entropy in the saturated region. 
Table 9. Predicting of thermodynamic properties(Cubic Spline Curve Fitting Method was utilized) and deviations for R410A refrigerant in saturated liquid region

\begin{tabular}{|c|c|c|c|c|c|c|c|c|c|c|}
\hline $\mathrm{T}(\mathrm{K})$ & $\mathrm{P}(\mathrm{MPa})$ & $\begin{array}{c}\text { REFPROP } 9.0 \\
\text { Estimated } \\
\text { Values for } \\
\rho(\mathrm{kgm}-3)\end{array}$ & $\begin{array}{c}\text { REF ISO17584 } \\
\text { Estimated } \\
\text { Values for } \\
\rho(\mathrm{kgm}-3)\end{array}$ & $\begin{array}{c}\text { Mean Deviation } \\
(\%)\end{array}$ & $\begin{array}{c}\text { REFPROP } 9.0 \\
\text { Estimated } \\
\text { Values for } \\
\mathrm{h}(\mathrm{kjkg}-1)\end{array}$ & $\begin{array}{c}\text { REF ISO17584 } \\
\text { Estimated } \\
\text { Values for } \\
\text { h(kjkg-1) }\end{array}$ & $\begin{array}{c}\text { Mean Deviation } \\
(\%)\end{array}$ & $\begin{array}{c}\text { REFPROP } 9.0 \\
\text { Estimated Values } \\
\text { for s(kjkg-1K-1) }\end{array}$ & $\begin{array}{c}\text { REF ISO17584 } \\
\text { Estimated Values } \\
\text { for s(kjkg-1K-1) }\end{array}$ & $\begin{array}{c}\text { Mean Deviation } \\
(\%)\end{array}$ \\
\hline 210 & 0,053727 & 1385,9 & 1385,909 & 0,000649393 & 110,51 & 110,379 & 0,118541308 & 0,63072 & 0,63069 & 0,004756469 \\
\hline 215 & 0,071143 & 1370,5 & 1370,61 & 0,008025624 & 117,31 & 117,174 & 0,115932146 & 0,66264 & 0,66213 & 0,076964868 \\
\hline 220 & 0,092819 & 1354,9 & 1355 & 0,007380074 & 124,13 & 124,022 & 0,087005559 & 0,69394 & 0,69344 & 0,072052339 \\
\hline 225 & 0,11946 & 1339,2 & 1339,28 & 0,005973359 & 130,99 & 130,865 & 0,095427132 & 0,72466 & 0,72415 & 0,070377832 \\
\hline 230 & 0,15182 & 1323,1 & 1323,26 & 0,01209135 & 137,88 & 137,77 & 0,079779518 & 0,75485 & 0,7544 & 0,059614493 \\
\hline 235 & 0,1907 & 1306,9 & 1306,96 & 0,004590806 & 144,82 & 144,72 & 0,069051236 & 0,78456 & 0,78416 & 0,050983991 \\
\hline 240 & 0,23697 & 1290,3 & 1290,4 & 0,007749535 & 151,81 & 151,728 & 0,054014887 & 0,81384 & 0,81355 & 0,03563354 \\
\hline 245 & 0,29152 & 1273,4 & 1273,53 & 0,010207847 & 158,85 & 158,788 & 0,039030532 & 0,84272 & 0,84255 & 0,020172774 \\
\hline 250 & 0,35531 & 1256,1 & 1256,2 & 0,007960516 & 165,96 & 165,91 & 0,030127742 & 0,87126 & 0,8686 & 0,305304961 \\
\hline 255 & 0,42933 & 1238,4 & 1238,48 & 0,006459531 & 173,15 & 173,11 & 0,023101357 & 0,89948 & 0,8993 & 0,020011562 \\
\hline 260 & 0,51461 & 1220,3 & 1220,33 & 0,002458351 & 180,42 & 180,39 & 0,016627868 & 0,92744 & 0,9273 & 0,015095316 \\
\hline 265 & 0,61223 & 1201,6 & 1201,656 & 0,004660236 & 187,78 & 187,76 & 0,010650762 & 0,95517 & 0,95506 & 0,011516275 \\
\hline 270 & 0,7233 & 1182,4 & 1182,43 & 0,002537148 & 195,24 & 195,245 & 0,002560885 & 0,98272 & 0,9827 & 0,002035168 \\
\hline 275 & 0,84899 & 1162,5 & 1162,56 & 0,005161024 & 202,82 & 202,818 & 0,000986096 & 1,0101 & 1,01 & 0,00990001 \\
\hline 280 & 0,99048 & 1141,9 & 1141,85 & 0,004378667 & 210,52 & 210,518 & 0,000950029 & 1,0375 & 1,0374 & 0,009638554 \\
\hline 285 & 1,149 & 1120,4 & 1120,29 & 0,009817922 & 218,37 & 218,39 & 0,009157928 & 1,0647 & 1,06486 & 0,015025449 \\
\hline 290 & 1,326 & 1098 & 1097,79 & 0,019125683 & 226,38 & 226,39 & 0,004417156 & 1,092 & 1,0921 & 0,009156671 \\
\hline 295 & 1,5226 & 1074,4 & 1074,22 & 0,016753537 & 234,57 & 234,59 & 0,008525513 & 1,1194 & 1,1195 & 0,008932559 \\
\hline 300 & 1,7404 & 1049,5 & 1049,24 & 0,024773702 & 242,97 & 242,99 & 0,008230791 & 1,147 & 1,1468 & 0,017436792 \\
\hline 305 & 1,9809 & 1023,1 & 1022,73 & 0,036164598 & 251,61 & 251,64 & 0,011921793 & 1,1748 & 1,1746 & 0,017024174 \\
\hline 310 & 2,2456 & 994,74 & 994,35 & 0,039206225 & 260,53 & 260,55 & 0,00767607 & 1,2029 & 1,2027 & 0,016626486 \\
\hline 315 & 2,5364 & 964,04 & 963,7 & 0,035268246 & 269,8 & 269,77 & 0,011119348 & 1,2316 & 1,2315 & 0,008119519 \\
\hline 320 & 2,855 & 930,28 & 930,015 & 0,028486047 & 279,49 & 279,47 & 0,007155891 & 1,2611 & 1,261 & 0,007929585 \\
\hline 325 & 3,2037 & 892,34 & 892,276 & 0,007172154 & 289,76 & 289,704 & 0,019326339 & 1,2917 & 1,2915 & 0,015483471 \\
\hline 330 & 3,5848 & 848,18 & 848,224 & 0,005187309 & 300,85 & 300,796 & 0,017949144 & 1,3243 & 1,324 & 0,022653477 \\
\hline 335 & 4,0009 & 793,36 & 793,499 & 0,01751735 & 313,31 & 313,24 & 0,022342089 & 1,3602 & 1,3599 & 0,02205558 \\
\hline 340 & 4,4556 & 714,34 & 714,41 & 0,009798295 & 328,81 & 329,095 & 0,086601133 & 1,4043 & 1,4052 & 0,064047822 \\
\hline
\end{tabular}


Table 10. Predicting of thermodynamic properties (Cubic Spline Curve Fitting Method was utilized) and deviations for R1234yf refrigerant in saturated liquid region

\begin{tabular}{|c|c|c|c|c|c|c|c|c|c|c|}
\hline $\mathrm{T}(\mathrm{K})$ & $\mathrm{P}(\mathrm{MPa})$ & $\begin{array}{c}\text { REFPROP } 9.0 \\
\text { Estimated } \\
\text { Values for } \\
\rho(\mathrm{kgm}-3)\end{array}$ & $\begin{array}{c}\text { REF ISO17584 } \\
\text { Estimated } \\
\text { Values for } \\
\rho(\mathrm{kgm}-3) \\
\end{array}$ & $\begin{array}{c}\text { Mean Deviation } \\
(\%)\end{array}$ & $\begin{array}{l}\text { REFPROP } 9.0 \\
\text { Estimated Values } \\
\text { for h(kjkg-1) }\end{array}$ & $\begin{array}{l}\text { REF ISO17584 } \\
\text { Estimated Values } \\
\text { for h(kjkg-1) }\end{array}$ & $\begin{array}{c}\text { Mean Deviation } \\
(\%)\end{array}$ & $\begin{array}{l}\text { REFPROP } 9.0 \\
\text { Estimated Values } \\
\text { for s(kjkg-1K-1) }\end{array}$ & $\begin{array}{c}\text { REF ISO17584 } \\
\text { Estimated Values } \\
\text { for s(kjkg-1K-1) }\end{array}$ & $\begin{array}{c}\text { Mean Deviation } \\
(\%)\end{array}$ \\
\hline 230 & 0,053393 & 1300,3 & 1300,2 & 0,007690533 & $-15,99$ & $-16,01$ & 0,124921924 & $-0,067365$ & $-0,06736$ & 0,007422803 \\
\hline 235 & 0,068172 & 1286,9 & 1286,7 & 0,015541223 & $-10,206$ & $-10,199$ & 0,06863418 & $-0,042538$ & $-0,0425$ & 0,089411765 \\
\hline 240 & 0,086032 & 1273,2 & 1272,9 & 0,023562677 & $-4,3456$ & $-4,3452$ & 0,00920556 & $-0,01792$ & $-0,01791$ & 0,055834729 \\
\hline 245 & 0,1074 & 1259,4 & 1259 & 0,031761156 & 1,5937 & 1,593 & 0,043942247 & 0,006503 & 0,00649 & 0,199907735 \\
\hline 250 & 0,13272 & 1245,3 & 1245 & 0,024090581 & 7,6131 & 7,6128 & 0,003940731 & 0,030742 & 0,03074 & 0,006505758 \\
\hline 255 & 0,16248 & 1231 & 1230,6 & 0,032493907 & 13,714 & 13,709 & 0,03647239 & 0,05481 & 0,05479 & 0,036489692 \\
\hline 260 & 0,19717 & 1216,3 & 1216,1 & 0,016443312 & 19,899 & 19,896 & 0,015078408 & 0,078718 & 0,078714 & 0,00508143 \\
\hline 265 & 0,2373 & 1201,4 & 1201 & 0,03329449 & 26,168 & 26,164 & 0,015288182 & 0,10248 & 0,10244 & 0,039032006 \\
\hline 270 & 0,28343 & 1186,1 & 1185,9 & 0,016861985 & 32,525 & 32,52 & 0,015375154 & 0,1261 & 0,12596 & 0,111022998 \\
\hline 275 & 0,33611 & 1170,5 & 1170,2 & 0,025630073 & 38,972 & 38,97 & 0,005132153 & 0,14959 & 0,14956 & 0,020054816 \\
\hline 280 & 0,39592 & 1154,4 & 1154,1 & 0,025987526 & 45,511 & 45,508 & 0,006592248 & 0,17297 & 0,17294 & 0,017344048 \\
\hline 285 & 0,46346 & 1137,9 & 1137,7 & 0,017576237 & 52,145 & 52,143 & 0,003835606 & 0,19624 & 0,19622 & 0,010191602 \\
\hline 290 & 0,53934 & 1120,9 & 1120,6 & 0,026764207 & 58,879 & 58,876 & 0,005095455 & 0,21943 & 0,2194 & 0,013671786 \\
\hline 295 & 0,62421 & 1103,3 & 1103 & 0,027191154 & 65,714 & 65,71 & 0,006087354 & 0,24254 & 0,24251 & 0,012369094 \\
\hline 300 & 0,71872 & 1085,1 & 1084,8 & 0,027647221 & 72,658 & 72,656 & 0,002752698 & 0,26559 & 0,26556 & 0,011295606 \\
\hline 305 & 0,82355 & 1066,2 & 1066 & 0,018758207 & 79,714 & 79,71 & 0,005018191 & 0,28859 & 0,28856 & 0,010395371 \\
\hline 310 & 0,93941 & 1046,6 & 1046,3 & 0,028664246 & 86,891 & 86,888 & 0,003452721 & 0,31158 & 0,31155 & 0,009628346 \\
\hline 315 & 1,067 & 1026,1 & 1025,8 & 0,029236916 & 94,198 & 94,194 & 0,004246555 & 0,33456 & 0,33452 & 0,011956002 \\
\hline 320 & 1,2072 & 1004,6 & 1004,2 & 0,039816843 & 101,65 & 101,6 & 0,049212598 & 0,3576 & 0,3572 & 0,111856823 \\
\hline 325 & 1,3607 & 981,81 & 981,78 & 0,003055581 & 109,27 & 109,23 & 0,036619976 & 0,38074 & 0,3807 & 0,010505857 \\
\hline 330 & 1,5285 & 957,56 & 957,5 & 0,006265926 & 117,07 & 117 & 0,05982906 & 0,40404 & 0,404 & 0,00990001 \\
\hline 335 & 1,7114 & 931,42 & 931,36 & 0,006441777 & 125,1 & 124,8 & 0,240384615 & 0,42761 & 0,42756 & 0,011692898 \\
\hline 340 & 1,9104 & 902,83 & 902,72 & 0,012183911 & 133,4 & 133 & 0,30075188 & 0,45156 & 0,4515 & 0,013287271 \\
\hline 345 & 2,1266 & 871,03 & 870,96 & 0,008036463 & 142,04 & 142 & 0,028169014 & 0,47606 & 0,476 & 0,012603453 \\
\hline 350 & 2,3614 & 834,85 & 834,8 & 0,0059891 & 151,11 & 151,02 & 0,059594756 & 0,50136 & 0,50131 & 0,009972874 \\
\hline 355 & 2,6162 & 792,31 & 792,26 & 0,006310661 & 160,8 & 160,72 & 0,049776008 & 0,52796 & 0,5279 & 0,011364497 \\
\hline 360 & 2,8931 & 738,91 & 738,86 & 0,006766724 & 171,53 & 171,41 & 0,070007584 & 0,55698 & 0,55695 & 0,00538619 \\
\hline
\end{tabular}


Table 11. Predicting of thermodynamic properties (cubic spline curve fitting method was utilized) and deviations for R410A refrigerant in saturated vapor region

\begin{tabular}{|c|c|c|c|c|c|c|c|c|c|c|}
\hline $\mathrm{T}(\mathrm{K})$ & $\mathrm{P}(\mathrm{MPa})$ & $\begin{array}{c}\text { REFPROP } 9.0 \\
\text { Estimated } \\
\text { Values for } \\
\rho(\mathrm{kgm}-3)\end{array}$ & $\begin{array}{c}\text { REF ISO17584 } \\
\text { Estimated } \\
\text { Values for } \\
\rho(\mathrm{kgm}-3)\end{array}$ & Mean Deviation (\%) & $\begin{array}{c}\text { REFPROP } 9.0 \\
\text { Estimated } \\
\text { Values for } \\
\mathrm{h}(\mathrm{kjkg}-1)\end{array}$ & $\begin{array}{c}\text { REF ISO17584 } \\
\text { Estimated } \\
\text { Values for } \\
\text { h(kjkg-1) }\end{array}$ & $\begin{array}{c}\text { Mean Deviation } \\
(\%)\end{array}$ & $\begin{array}{c}\text { REFPROP } 9.0 \\
\text { Estimated } \\
\text { Values for } \\
\mathrm{s}(\mathrm{kjkg}-1 \mathrm{~K}-1)\end{array}$ & $\begin{array}{l}\text { REF ISO17584 } \\
\text { Estimated Values } \\
\text { for s(kjkg-1K-1) }\end{array}$ & Mean Deviation (\%) \\
\hline 210 & 0,053489 & 2,2913 & 2,2921 & 0,034902491 & 393,05 & 392,998 & 0,013229869 & 1,9763 & 1,976 & 0,015179882 \\
\hline 215 & 0,070844 & 2,9824 & 2,984 & 0,053619303 & 395,76 & 395,72 & 0,010107136 & 1,9579 & 1,9578 & 0,005107513 \\
\hline 220 & 0,092447 & 3,8298 & 3,832 & 0,057411273 & 398,41 & 398,357 & 0,013302879 & 1,9408 & 1,9406 & 0,010305029 \\
\hline 225 & 0,119 & 4,8578 & 4,859 & 0,02469644 & 401 & 400,96 & 0,009975062 & 1,9249 & 1,9248 & 0,005195075 \\
\hline 230 & 0,15125 & 6,0926 & 6,094 & 0,022973416 & 403,53 & 403,49 & 0,009912522 & 1,91 & 1,9099 & 0,005235602 \\
\hline 235 & 0,19 & 7,5632 & 7,5656 & 0,031722534 & 405,98 & 405,946 & 0,008374797 & 1,896 & 1,89594 & 0,003164557 \\
\hline 240 & 0,23611 & 9,3012 & 9,3018 & 0,006450364 & 408,35 & 408,308 & 0,010285294 & 1,8829 & 1,8828 & 0,005310957 \\
\hline 245 & 0,29049 & 11,341 & 11,348 & 0,061684878 & 410,63 & 410,584 & 0,011202299 & 1,8705 & 1,8704 & 0,005346164 \\
\hline 250 & 0,35407 & 13,722 & 13,7268 & 0,034968092 & 412,82 & 412,767 & 0,012838525 & 1,8588 & 1,85868 & 0,006455778 \\
\hline 255 & 0,42786 & 16,487 & 16,49 & 0,018192844 & 414,9 & 414,839 & 0,014702338 & 1,8476 & 1,84749 & 0,00595367 \\
\hline 260 & 0,51287 & 19,683 & 19,688 & 0,02539618 & 416,87 & 416,799 & 0,017031689 & 1,8369 & 1,8367 & 0,010887909 \\
\hline 265 & 0,61019 & 23,365 & 23,369 & 0,017116693 & 418,7 & 418,633 & 0,016001911 & 1,8267 & 1,8265 & 0,010948705 \\
\hline 270 & 0,72092 & 27,596 & 27,602 & 0,021737555 & 420,4 & 420,32 & 0,019029496 & 1,8167 & 1,8165 & 0,011008972 \\
\hline 275 & 0,84622 & 32,447 & 32,45 & 0,009244992 & 421,94 & 421,84 & 0,023700052 & 1,807 & 1,8067 & 0,016602103 \\
\hline 280 & 0,98729 & 38,003 & 38,012 & 0,023676734 & 423,3 & 423,2 & 0,023623907 & 1,7974 & 1,797 & 0,022254367 \\
\hline 285 & 1,1454 & 44,367 & 44,372 & 0,011268367 & 424,45 & 424,36 & 0,021203911 & 1,7879 & 1,7876 & 0,016779462 \\
\hline 290 & 1,3218 & 51,659 & 51,664 & 0,009677919 & 425,38 & 425,28 & 0,023508392 & 1,7783 & 1,778 & 0,016870044 \\
\hline 295 & 1,5179 & 60,033 & 60,043 & 0,016654731 & 426,05 & 425,93 & 0,028165708 & 1,7686 & 1,7682 & 0,022616759 \\
\hline 300 & 1,7351 & 69,68 & 69,702 & 0,031562939 & 426,41 & 426,27 & 0,032832251 & 1,7585 & 1,758 & 0,028433324 \\
\hline 305 & 1,9749 & 80,849 & 80,852 & 0,003710483 & 426,41 & 426,26 & 0,035177411 & 1,748 & 1,7474 & 0,034324943 \\
\hline 310 & 2,239 & 93,875 & 93,879 & 0,004260804 & 425,98 & 425,804 & 0,041316494 & 1,7367 & 1,7362 & 0,028790234 \\
\hline 315 & 2,5291 & 109,22 & 109,25 & 0,027459954 & 425,02 & 424,827 & 0,045409628 & 1,7245 & 1,72387 & 0,036532328 \\
\hline 320 & 2,8472 & 127,58 & 127,61 & 0,023509129 & 423,39 & 423,186 & 0,048182527 & 1,7108 & 1,7102 & 0,035071312 \\
\hline 325 & 3,1955 & 150,02 & 150,12 & 0,066613376 & 420,86 & 420,657 & 0,048234567 & 1,6952 & 1,6946 & 0,035394054 \\
\hline 330 & 3,5766 & 178,43 & 178,48 & 0,028014343 & 417,06 & 416,877 & 0,043878579 & 1,6765 & 1,6759 & 0,035788846 \\
\hline 335 & 3,9935 & 216,65 & 216,69 & 0,018459551 & 411,22 & 411,073 & 0,035747289 & 1,6525 & 1,6523 & 0,012102874 \\
\hline 340 & 4,4504 & 275,64 & 275,71 & 0,025388996 & 401,22 & 401,1 & 0,029908778 & 1,6173 & 1,6172 & 0,006183145 \\
\hline
\end{tabular}


Table 12. Predicting of thermodynamic properties(Cubic Spline Curve Fitting Method was utilized) and deviations for R1234yf refrigerant in saturated vapor region

\begin{tabular}{|c|c|c|c|c|c|c|c|c|c|c|}
\hline $\mathrm{T}(\mathrm{K})$ & $\mathrm{P}(\mathrm{MPa})$ & $\begin{array}{c}\text { REFPROP } 9.0 \\
\text { Estimated } \\
\text { Values for } \\
\rho(\mathrm{kgm}-3)\end{array}$ & $\begin{array}{c}\text { REF ISO17584 } \\
\text { Estimated } \\
\text { Values for } \\
\rho(\mathrm{kgm}-3)\end{array}$ & $\begin{array}{c}\text { Mean Deviation } \\
(\%)\end{array}$ & $\begin{array}{c}\text { REFPROP } 9.0 \\
\text { Estimated } \\
\text { Values for } \\
\text { h(kjkg-1) }\end{array}$ & $\begin{array}{c}\text { REF ISO17584 } \\
\text { Estimated } \\
\text { Values for } \\
\text { h(kjkg-1) }\end{array}$ & $\begin{array}{c}\text { Mean Deviation } \\
(\%)\end{array}$ & $\begin{array}{l}\text { REFPROP } 9.0 \\
\text { Estimated Values } \\
\text { for s(kjkg-1K-1) }\end{array}$ & $\begin{array}{c}\text { REF ISO17584 } \\
\text { Estimated Values for } \\
\text { s(kjkg-1K-1) }\end{array}$ & $\begin{array}{c}\text { Mean Deviation } \\
(\%)\end{array}$ \\
\hline 230 & 0,053393 & 3,2814 & 3,281 & 0,012189919 & 171,03 & 171 & 0,017540782 & 0,74577 & 0,74576 & 0,001340896 \\
\hline 235 & 0,068172 & 4,1242 & 4,122 & 0,053343679 & 174,4 & 174,2 & 0,114678899 & 0,74303 & 0,743 & 0,004037522 \\
\hline 240 & 0,086032 & 5,1292 & 5,1288 & 0,007798487 & 177,77 & 177,72 & 0,028126231 & 0,74091 & 0,74088 & 0,004049075 \\
\hline 245 & 0,1074 & 6,3179 & 6,3174 & 0,007914022 & 181,15 & 181,06 & 0,049682583 & 0,73937 & 0,73934 & 0,004057508 \\
\hline 250 & 0,13272 & 7,7131 & 7,7124 & 0,009075469 & 184,51 & 184,48 & 0,016259281 & 0,73834 & 0,73832 & 0,002708779 \\
\hline 255 & 0,16248 & 9,3398 & 9,3394 & 0,004282747 & 187,87 & 187,82 & 0,026614148 & 0,73776 & 0,73772 & 0,005421817 \\
\hline 260 & 0,19717 & 11,225 & 11,222 & 0,026726058 & 191,2 & 191,06 & 0,073221757 & 0,73759 & 0,73756 & 0,0040673 \\
\hline 265 & 0,2373 & 13,399 & 13,394 & 0,037316218 & 194,52 & 194,48 & 0,020563438 & 0,73777 & 0,73774 & 0,004066308 \\
\hline 270 & 0,28343 & 15,894 & 15,89 & 0,02516673 & 197,81 & 197,79 & 0,010110712 & 0,73827 & 0,73824 & 0,004063554 \\
\hline 275 & 0,33611 & 18,746 & 18,742 & 0,021337885 & 201,07 & 201,04 & 0,014920177 & 0,73903 & 0,739 & 0,004059375 \\
\hline 280 & 0,39592 & 21,996 & 21,994 & 0,009092562 & 204,28 & 204,26 & 0,009790484 & 0,74001 & 0,73999 & 0,002702666 \\
\hline 285 & 0,46346 & 25,688 & 25,686 & 0,007785737 & 207,44 & 207,41 & 0,014462013 & 0,74115 & 0,74112 & 0,004047764 \\
\hline 290 & 0,53934 & 29,877 & 29,875 & 0,006694113 & 210,55 & 210,51 & 0,018997863 & 0,74243 & 0,74241 & 0,002693857 \\
\hline 295 & 0,62421 & 34,62 & 34,614 & 0,017331023 & 213,58 & 213,55 & 0,014046259 & 0,74377 & 0,74374 & 0,004033505 \\
\hline 300 & 0,71872 & 39,989 & 39,987 & 0,005001375 & 216,52 & 216,5 & 0,009237022 & 0,74514 & 0,7451 & 0,005368119 \\
\hline 305 & 0,82355 & 46,066 & 46,062 & 0,008683194 & 219,37 & 219,34 & 0,013675525 & 0,74647 & 0,74645 & 0,002679277 \\
\hline 310 & 0,93941 & 52,949 & 52,945 & 0,007554439 & 222,1 & 221,94 & 0,072039622 & 0,74772 & 0,74669 & 0,1377521 \\
\hline 315 & 1,067 & 60,76 & 60,754 & 0,009874918 & 224,69 & 224,684 & 0,002670346 & 0,74882 & 0,7488 & 0,002670869 \\
\hline 320 & 1,2072 & 69,648 & 69,645 & 0,004307374 & 227,12 & 227 & 0,052835505 & 0,74969 & 0,74964 & 0,006669423 \\
\hline 325 & 1,3607 & 79,803 & 79,799 & 0,005012343 & 229,36 & 229,33 & 0,013079874 & 0,75026 & 0,75021 & 0,006664356 \\
\hline 330 & 1,5285 & 91,475 & 91,471 & 0,004372779 & 231,38 & 231,34 & 0,017287579 & 0,75042 & 0,75039 & 0,003997761 \\
\hline 335 & 1,7114 & 105 & 104,96 & 0,038095238 & 233,11 & 233 & 0,047188023 & 0,75003 & 0,75 & 0,00399984 \\
\hline 340 & 1,9104 & 120,85 & 120,83 & 0,016549441 & 234,5 & 234,41 & 0,038379531 & 0,7489 & 0,7484 & 0,066764588 \\
\hline 345 & 2,1266 & 139,73 & 139,68 & 0,035783296 & 235,43 & 235,4 & 0,012742641 & 0,74675 & 0,7467 & 0,006695681 \\
\hline 350 & 2,3614 & 162,79 & 162,74 & 0,030714417 & 235,73 & 235,68 & 0,021210707 & 0,74315 & 0,74306 & 0,01211061 \\
\hline 355 & 2,6162 & 192,12 & 192 & 0,062460962 & 235,11 & 234,99 & 0,051039939 & 0,7373 & 0,73722 & 0,0108504 \\
\hline 360 & 2,8931 & 232,37 & 232,32 & 0,021517408 & 232,91 & 232,85 & 0,025761024 & 0,72746 & 0,72741 & 0,00687323 \\
\hline
\end{tabular}


Table 13. Mean deviations of R1234yf thermal properties for the regions of a refrigerant fluid

\begin{tabular}{|c|c|c|c|c|}
\hline \multirow{3}{*}{ Parameters } & \multicolumn{4}{|c|}{ Mean deviations (\%) } \\
\hline & \multirow[t]{2}{*}{ Subcooled } & \multicolumn{2}{|c|}{ Saturated } & \multirow[t]{2}{*}{ Superheated } \\
\hline & & Liquid & Vapor & \\
\hline Density $\left(\mathrm{kg} \cdot \mathrm{m}^{-3}\right)$ & 0,1288 & 0,0194 & 0,0183 & 0,21957 \\
\hline Specific enthalpy $\left(\mathrm{kJ} \mathrm{kg}^{-1}\right)$ & 0,2183 & 0,047 & 0,032 & 0,1906 \\
\hline Specific entropy $\left(\mathrm{kJ} . \mathrm{kg}^{-1} \cdot \mathrm{K}^{-1}\right)$ & 0,1443 & 0,032 & 0,012 & 0,1461 \\
\hline
\end{tabular}

Table 14. Mean deviations of R410A thermal properties for the regions of a refrigerant fluid

\begin{tabular}{ccccc}
\hline \multirow{2}{*}{ Parameters } & \multicolumn{3}{c}{ Mean deviations (\%) } \\
\cline { 2 - 4 } & Subcooled & \multicolumn{2}{c}{ Saturated } & Superheated \\
\cline { 2 - 4 } & & Liquid & Vapor & \multirow{2}{*}{0,0232} \\
\cline { 3 - 4 } Density $\left(\mathrm{kg} \cdot \mathrm{m}^{-3}\right)$ & 0,045 & 0,01257 & 0,0263 & 0,0132 \\
Specific enthalpy $\left(\mathrm{kJ} \cdot \mathrm{kg}^{-1}\right)$ & 0,1276 & 0,0354 & 0,02395 & 0,0203 \\
\hline Specific entropy $\left(\mathrm{kJ} \cdot \mathrm{kg}^{-1} \cdot \mathrm{K}^{-1}\right)$ & 0,0283 & 0,0366 & 0,0165 & 0 \\
\hline
\end{tabular}

In addition, the accurate effects of the developed computer program were shown in Table 13 and table 14 as mean deviations in the calculated thermal properties of R1234yf and $\mathrm{R} 410 \mathrm{~A}$ respectively.

\section{Conclusions}

A new developed program (Refrigerant) for the calculation of thermodynamic properties of pure refrigerants and refrigerant mixtures were presented in this study. The program was modeled with two different approaches: Helmholtz equation of state $(H E O S)$ and cubic spline curve fitting method (CSCFM). Separate equations of these approaches were used for modeling different regions and properties. One of these methods (HEOS) was used to calculate in subcooled liquid and superheated vapor phases, and the other (CSCFM) to calculate saturated and mixed phases. For the superheated and subcooled states, the pressure, specific enthalpy, specific entropy and specific volume can be determined when the temperature and one of the other thermal properties were known. Also for two-phase refrigerant state, the pressure, specific enthalpy, specific entropy and specific volume can be determined when the temperature was also given as an input parameter with the vapor quality.

As an example refrigerant, R1234yf and R410A were used in the study. The source data for regressing was obtained from REFPROP 9.0. With the new model, thermodynamic properties of R1234yf and R410A were predicted and compared with REFPROP 9.0[14]. It was cleared that the total mean relative deviations of the new model were less than $0.5 \%$. Table 13 and table 14 probed that the agreement between the calculated properties with those from
REFPROP 9.0 was satisfactory. It was shown that the absolute deviations of the calculated thermal properties were always very low and within the uncertainties of the source data used for comparison and accuracy evaluation. For these reasons, this region of the saturation curve was excluded from the analysis. Each refrigerant and thermodynamic property is treated in a similar way, so the method can be easily programmed and extended to other refrigerants.

The field of refrigerant property research has seen tremendous activity in recent years. While significant progress has been made, property models for refrigerants, particularly those for mixtures, are still under development, and the coming years promise still better models. Each model will have its own strengths and weaknesses in the future. Simpler methods, such as cubic spline curve fitting method and Helmholtz equation of state method, also have their place, provided that they are validated against data and used within their limits of applicability.

Thermodynamic properties of refrigerants calculated by using Helmholtz Equation of State given as standard equation for refrigerants in ISO17584:2005(E) by using simulation programs developed in java programming language. This equation of state requires only derivatives. Therefore it is easier to calculate compare to pressure type equation of states. The results obtained from ISO17584 EOS and a commercial package REFPROP 9.0 is compared with standard printed tables for refrigerant R1234yf, refrigerant mixture R410A and it is found that error ranges are not big. It should be not that standard printed tables might have some errors as well. Property calculations are a continuous process of improvement and error reduction. The developed programs will be presented as public access programs for everybody to use as tables and as system simulation tools in 
250 Modeling of Thermodynamic Properties for Pure Refrigerants and Refrigerant Mixtures by Using the Helmholtz Equation of State and Cubic Spline Curve Fitting Method

their own system simulations.

\section{Nomenclature}

$T$ - Temperature, $\mathrm{K}$

$P$ - Pressure, $\mathrm{kPa}$

$v$ - Specific volume, $\mathrm{m}^{3} \mathrm{~kg}^{-1}$

$s$ - Entropy, $\mathrm{kj} \mathrm{kg}^{-1} \mathrm{~K}^{-1}$

$u$ - Internal Energy, $\mathrm{kj} \mathrm{kg}^{-1}$

$h$ - Enthalpy, $\mathrm{kj} \mathrm{kg}^{-1}$

$x$ - Quality, kg vapor ( $\mathrm{kg}$ mix. $)^{-1}$

$C p$ - Specific heat for constant pressure $\mathrm{kj} \mathrm{kg}^{-1} \mathrm{~K}^{-1}$

$C p_{i d}$ Heat capacity of ideal gas state, $\mathrm{kj} \mathrm{kg}^{-1} \mathrm{~K}^{-1}$

$C v$-Specific heat for constant volume, $\mathrm{kj} \mathrm{kg}^{-1} \mathrm{~K}^{-1}$

$R$ - Real Gas constant, $\mathrm{kj} \mathrm{kg}^{-1} \mathrm{~K}^{-1}$

$M$ - Molar mass, $\mathrm{g}(\mathrm{mol})^{-1}$

$T^{*}$ - Reducing parameter which is often equal to the critical parameter

$k$ - Constant $(1,2, \ldots, \mathrm{n})$

$N_{k}$ - Numerical coefficients which is fitted to experimental data

$\alpha_{k}, \beta_{k}, \varepsilon_{k}, \gamma_{k^{-}}$Certain multipliers for special refrigerant (Obtained by curve fitting)

$t_{k}, d_{k}, l_{k}, m_{k^{-}}$Certain upper coefficients for special refrigerant (Obtained by curve fitting)

$c_{k}, a_{k}, t_{k}$ - Numerical coefficients fitted to data or derived from theoretical calculations

$h_{\text {ref }}$ - Ideal gas reference enthalpy, $\mathrm{kj} \mathrm{kg}^{-1}$

$s_{\text {ref }}$ - Ideal gas reference entropy, $\mathrm{kj} \mathrm{kg}^{-1} \mathrm{~K}^{-1}$

$g$ - Gibbs free energy

\section{Greek Symbols}

$\tau$ - Dimensionless temperature variable, $T^{*} T^{l}$

$\delta$ - Dimensionless density variable, $\rho \rho^{*^{-1}}$

$\rho$ - Density, $\mathrm{kg} \mathrm{m}^{-3}$

$\rho^{*}$ - Reducing parameter which is often equal to the critical parameter

$\phi$ - Helmholtz equation function

$\phi_{r}$ - Real gas Helmholtz equation function

$\phi_{i d}$ - Ideal gas Helmholtz equation function

$x_{i}$ - Mole fraction of component $i$ in the $n$-component mixture

$\zeta_{i j}, \xi_{i j}$ - Interaction parameters

$T_{i}^{*}, \rho_{i}^{*}$ - Reducing parameters of pure fluids.

\section{Subscript}

$i d$ - Ideal gas behavior

$r$ - Real gas behavior

$a$ - Residual

\section{Abbreviations}

EOS- Equation Of State ref- Reference

$I S O$ - International Standard Organization

App.- Application

$H E o S$ - Helmholtz Equation of State

CSCFM- Cubic Spline Curve Fitting Method

\section{Acknowledgements}

We are thankful to Dr. Frank Rinne (Technical Programs Manager Refrigerants EMEA) and Technical Committee ISO/TC 86, Refrigeration and Air- Conditioning Subcommittee SC8, Refrigerants and Refrigeration Lubricants for prepared ISO17584(International Standard).

\section{REFERENCES}

[1] Akasaka, R., Tanaka, K., Higashi, Y. ,2010. Thermodynamic property modeling for 2,3,3,3- Tetrafluoropropene (HFO1234yf). Int. J. Refrigeration 33(1), 52-60.

[2] Chan, C.Y., Haselden, G.G., 1981. Computer- based refrigerant thermodynamic properties. Part1. Basic equations. Int. J. Refrigeration 4 (1), 7-12.

[3] Charters, W.W.S., Sadafi H.A., 1987. Saturation property equation for R22. Int. J. Refrigeration 10 (2) 103-104.

[4] Cleland, A.C.,1986. Computer subroutines for rapid evaluation of refrigerant thermodynamic properties. Int. J. Refrigeration 9 (8), 346-351.

[5] Cleland, A.C.,1994. Polynomial curve-fits for refrigerant thermodynamic properties: extension to include R134a. Int. J. Refrigeration 17 (4), 245-249.

[6] Devotta, S., Pendyala, V.R.,1994. Prediction of volumetric and thermodynamic properties of refrigerants: a simplified procedure. Int. J. Refrigeration 17 (2), 94-100.

[7] Ding, G., Wu, Z., Liu, J., Inagaki, T., Wang, K., Fukaya, M.,2005. An implicit curve-fitting method for fast calculation of thermal properties of pure and mixed refrigerants. Int. J. Refrigeration 28 (6), 921-932.

[8] Ding, G., Wu, Z., Wang, K., Fukaya, M.,2007. Extension of the applicable range of the implicit curve-fitting method for refrigerant thermodynamic properties to critical pressure. Int. J. Refrigeration 30 (3), 418-432.

[9] Fernandes, J.L.M.,1996. Fast evaluation of thermodynamic properties of superheated steam: a cubic equation of state. Appl. Therm. Eng. 16 (1), 71-79.

[10] Froba, A.P., Leipertz, A.,2003. Thermophysical properties of the refrigerant mixtures $\mathrm{R} 410 \mathrm{~A}$ and $\mathrm{R} 407 \mathrm{C}$ from dynamic light scattering, Int. J. of Thermophysics, Volume 24, Issue 5, 1185-1206.

[11] Huber, M.L., Ely, J.F.,1994. An equation of state formulation of the thermodynamic properties of R134a. Int. J. Refrigeration 17, 18-31.

[12] International standard ISO 17584 refrigerant properties, 2005, 
reference number: ISO 17584:2005(E)

[13] Küçüksille, E.U., Selbaş, R., Şencan, A.,2011. Prediction of thermodynamic properties of refrigerants using data mining. Energy Convers. Manage. 52, 836-848.

[14] Lemmon, E.W., Huber, M.L., McLinden, M.O.,2010. NIST Standard Reference Database 23: Reference fluid thermodynamic and transport properties, REFPROP, Version 9.0. National Institute of Standards and Technology, Standard Reference Data Program, Gaithersburg.

[15] Lemmon, E. W., Tillner -Roth, R.,1999. A Helmholtz equation of state for calculating the thermodynamic properties of fluid mixtures. Fluid Phase Equilib.165, 1-21.

[16] Lemmon, E.W., Jacobsen, R.T.,2004. Equations of state for mixtures of R-32, R-125, R- 134a, R-143a, and R-152a. J. Phys. Chem. Ref. Data 33 (2), 593-620

[17] Lemmon, E.W., Jacobsen, R.T.,2005. A new fundamental form and new fitting techniques for equations of state with application to pentafluoroethane (HFC-125). J. Phys.Chem. Ref. Data 34(1), 69-108.

[18] Mahajan, A.J., Steward, R.B.,1992. The prediction of thermodynamic properties of the liquid- vapor coexistence states. Fluid Phase Equilib. 79, 63-75.

[19] Martin- Dominguez, I.R., McDonald, T.W.,1993. Correlations for some saturate thermodynamic and transport properties of refrigerant R-22. ASHRAE Trans 99, 344-348.

[20] McLinden, M.O., Lemmon, E.W., Jacobsen, R.T.,1998. Thermodynamic properties for the alternative refrigerants. Int. J. Refrigeration 21 (4), 322-338.

[21] ] Monte, F. de.,2002. Calculation of thermodynamic properties of R407C and R410A by the Martin-Hou equation of stated Part I. Theoretical development. Int. J. Refrigeration 25 (3), 306-313.

[22] Richter, M., Mclinden, M.O., Lemmon, E.W.,2011. Thermodynamic properties of 2,3,3,3-Tetrafluoroprop-1-ene (R1234yf): Vapor pressure and $\mathrm{p}-\rho$-T measurements and an equation of state. J.Chem.Eng.Data, 56,3254-3264.
[23] Saleh, B., Wendalnd, M.,2006. Screening of pure fluids as alternative refrigerants. Int. J. refrigeration, 29, 260-269.

[24] Sieres, J., Varas, F., Martinez-Suarez, J. A.,2012. A hybrid formulation for fast explicit alculation of thermodynamic properties of refrigerants. Int. J. Refrigeration, 35, 1021-1034.

[25] Sozen, A., Arcaklioglu, E. Menlik, T., Ozalp, M.,2009. Determination of thermodynamic properties of an alternative refrigerant (R407C) using artifical neural network. Expert Systems with Applications, Volume 36,Issue 3, Part 1, 4346-4356.

[26] Span, R.,2000. Multiparameter Equations of State An Accurate Source of Thermodynamic Property Data. Springer, Berlin, pp. 40-41.

[27] Span, R., Wagner, W.,1998. A new equation of state for carbon dioxide covering the fluid region from the triple-point to $1100 \mathrm{~K}$ at pressures up to $800 \mathrm{MPa}$. J. Phys. Chem. Ref. Data, Vol. 25,No:6.

[28] Stewart Richard B., Jacobsen, Richard T., Penoncello, Steven G.,2005.ASHRAE Thermodynamic Properties of Refrigerants

[29] Tanaka, K., Higashi, Y.,2010. Thermodynamic properties of HFO-1234yf (2,3,3,3- tetrafluoropropane) Int.J.Ref.,33,474479 .

[30] Tillner-Roth, R. and Baehr, H.D.,1994. An international standard formulation of the thermodynamic properties of 1,1,1,2-tetrafluoroethane (HFC-134a) covering temperatures from $170 \mathrm{~K}$ to $455 \mathrm{~K}$ at pressures up to $70 \mathrm{MPa}$, J. Phys. Chem. Ref. Data, 23, pp. 657-729.

[31] Tillner-Roth, R. and Yokozeki, 1997. A. An international standard equation of state for difluoromethane (R-32) for temperatures from the triple point at $136.34 \mathrm{~K}$ to $435 \mathrm{~K}$ and pressures up to $70 \mathrm{MPa}$, J. Phys. Chem. Ref. Data, 26, pp.1273-1328

[32] Zhao, D., Ding, G., Wu, Z.,2009. Extension of the implicit curve-fitting method for fast calculation of thermodynamic properties of refrigerants in supercritical region. Int. J. Ref., $32,1615-1625$. 